\title{
A Hybrid Proximal Point Three-Step Algorithm for Nonlinear Set-Valued Quasi-Variational Inclusions System Involving $(A, \eta)$-Accretive Mappings
}

\author{
Hong-Gang Li, ${ }^{1}$ An Jian Xu, ${ }^{1}$ and Mao Ming Jin' ${ }^{2}$ \\ ${ }^{1}$ Institute of Applied Mathematics Research, Chongqing University of Posts and TeleCommunications, \\ Chongqing 400065, China \\ 2 Institute of Nonlinear Analysis Research, Changjiang Normal University, Chongqing, \\ Fuling 400803, China
}

Correspondence should be addressed to Hong-Gang Li, lihg12@126.com

Received 29 December 2009; Accepted 7 April 2010

Academic Editor: Nanjing Jing Huang

Copyright (c) 2010 Hong-Gang Li et al. This is an open access article distributed under the Creative Commons Attribution License, which permits unrestricted use, distribution, and reproduction in any medium, provided the original work is properly cited.

The main purpose of this paper is to introduce and study a new class of generalized nonlinear setvalued quasi-variational inclusions system involving $(A, \eta)$-accretive mappings in Banach spaces. By using the resolvent operator due to Lan-Cho-Verma associated with $(A, \eta)$-accretive mappings and the matrix analysis method, we prove the convergence of a new hybrid proximal point three-step iterative algorithm for this system of set-valued variational inclusions and an existence theorem of solutions for this kind of the variational inclusions system. The results presented in this paper generalize, improve, and unify some recent results in this field.

\section{Introduction}

The variational inclusion, which was introduced and studied by Hassouni and Moudafi [1], is a useful and important extension of the variational inequality. It provides us with a unified, natural, novel, innovative, and general technique to study a wide class of problems arising in different branches of mathematical and engineering sciences. Various variational inclusions have been intensively studied in recent years. Ding and Luo [2], Verma [3, 4], Huang [5], Fang et al. [6], Fang and Huang [7], Fang et al. [8], Lan et al. [9], Zhang et al. [10] introduced the concepts of $\eta$-subdifferential operators, maximal $\eta$-monotone operators, $H$-monotone operators, $A$-monotone operators, $(H, \eta)$-monotone operators, $(A, \eta)$-accretive mappings, $(G, \eta)$-monotone operators, and defined resolvent operators associated with them, respectively. Moreover, by using the resolvent operator technique, many authors 
constructed some approximation algorithms for some nonlinear variational inclusions in Hilbert spaces or Banach spaces. Verma has developed a hybrid version of the EcksteinBertsekas [11] proximal point algorithm, introduced the algorithm based on the $(A, \eta)$ maximal monotonicity framework [12], and studied convergence of the algorithm. For the past few years, many existence results and iterative algorithms for various variational inequalities and variational inclusion problems have been studied. For details, please see [137] and the references therein.

On the other hand, some new and interesting problems for systems of variational inequalities were introduced and studied. Peng and Zhu [14], Cohen and Chaplais [15], Bianchi [16], and Ansari and Yao [17] considered a system of scalar variational inequalities. Ansari et al. [18] introduced and studied a system of vector equilibrium problems and a system of vector variational inequalities using a fixed point theorem. Allevi et al. [19] considered a system of generalized vector variational inequalities and established some existence results with relative pseudomonotonicity. Kassay and Kolumbán [20] introduced a system of variational inequalities and proved an existence theorem through the Ky Fan lemma. Kassay et al. [21] studied Minty and Stampacchia variational inequality systems with the help of the Kakutani-Fan-Glicksberg fixed point theorem. J. K. Kim and D. S. Kim [22] introduced a new system of generalized nonlinear quasi-variational inequalities and obtained some existence and uniqueness results on solutions for this system of generalized nonlinear quasi-variational inequalities in Hilbert spaces. Cho et al. [23] introduced and studied a new system of nonlinear variational inequalities in Hilbert spaces. They proved some existence and uniqueness theorems for solutions for the system of nonlinear variational inequalities. As generalizations of a system of variational inequalities, Agarwal et al. [24] introduced a system of generalized nonlinear mixed quasivariational inclusions and investigated the sensitivity analysis of solutions for this system of generalized nonlinear mixed quasi-variational inclusions in Hilbert spaces. Kazmi and Bhat [25] introduced a system of nonlinear variational-like inclusions and gave an iterative algorithm for finding its approximate solution. Fang and Huang [26], Fang et al. [8] introduced and studied a new system of variational inclusions involving H-monotone operators and $(H, \eta)$-monotone operators, respectively. Yan et al. [27] introduced and studied a system of set-valued variational inclusions which is more general than the model in [3].

Inspired and motivated by recent research work in this field, in this paper, a general set-valued quasi-variational inclusions system with $(A, \eta)$-accretive mappings is studied in Banach spaces, which includes many variational inclusions (inequalities) as special cases. By using the resolvent operator associated with $(A, \eta)$-accretive operator due to Lan, an existence theorem of solution for this class of variational inclusions is proved, and a new hybrid proximal point algorithm is established and suggested, and the convergence of iterative sequences generated by the algorithm is discussed in $q$-uniformly smooth Banach spaces. The results presented in this paper generalize, and unify some recent results in this field.

\section{Preliminaries}

Let $X$ be a real Banach space with dual space $X^{*},\langle\cdot, \cdot\rangle$ be the dual pair between $X$ and $X^{*}$, $2^{X}$ denote the family of all the nonempty subsets of $X$, and $C B(X)$ denote the family of all nonempty closed bounded subsets of $X$. The generalized duality mapping $J_{q}: X \rightarrow 2^{X^{*}}$ is 
defined by

$$
J_{q}(x)=\left\{f^{*} \in X^{*}:\left\langle x, f^{*}\right\rangle=\|x\|^{q},\left\|f^{*}\right\|=\|x\|^{q-1}\right\}, \quad \forall x \in X,
$$

where $q>1$ is a constant.

The modulus of smoothness of $X$ is the function $\rho_{X}:[0, \infty) \rightarrow[0, \infty)$ defined by

$$
\rho_{X}(t)=\sup \left\{\frac{1}{2}(\|x+y\|+\|x-y\|)-1:\|x\| \leq 1,\|y\| \leq t\right\} .
$$

A Banach space $X$ is called uniformly smooth if

$$
\lim _{t \rightarrow 0} \frac{\rho_{X}(t)}{t}=0
$$

$X$ is called $q$-uniformly smooth if there exists a constant $c>0$ such that

$$
\rho_{X}(t) \leq c t^{q}, \quad(q>1)
$$

Remark 2.1. In particular, $J_{2}$ is the usual normalized duality mapping. It is known that, $J_{q}(x)=$ $\|x\|^{q-2} J_{2}(x)$ for all $x \neq 0, J_{q}$ is single-valued if $X^{*}$ is strictly convex [10], or $X$ is uniformly smooth (Hilbert space and $L_{p}(2 \leq p<\infty)$ space are 2 uniformly Banach space), and if $X=\mathscr{l}$, the Hilbert space, then $J_{2}$ becomes the identity mapping on $H$. In what follows we always denote the single-valued generalized duality mapping by $J_{q}$ in real uniformly smooth Banach space $X$ unless otherwise states.

Let us recall the following results and concepts.

Definition 2.2. A single-valued mapping $\eta: X \times X \rightarrow X$ is said to be $\tau$-Lipschitz continuous if there exists a constant $\tau>0$ such that

$$
\|\eta(x, y)\| \leq \tau\|x-y\|, \quad \forall x, y \in X
$$

Definition 2.3. A single-valued mapping $A: X \rightarrow X$ is said to be

(i) accretive if

$$
\left\langle A\left(x_{1}\right)-A\left(x_{2}\right), J_{q}\left(x_{1}-x_{2}\right)\right\rangle \geq 0, \quad \forall x_{1}, x_{2} \in X
$$

(ii) strictly accretive if $A$ is accretive and $\left\langle A\left(x_{1}\right)-A\left(x_{2}\right), J_{q}\left(x_{1}-x_{2}\right)\right\rangle=0$ if and only if $x_{1}=x_{2}$ for all $x_{1}, x_{2} \in X$;

(iii) $r$-strongly $\eta$-accretive if there exists a constant $r>0$ such that

$$
\left\langle A\left(x_{1}\right)-A\left(x_{2}\right), J_{q}\left(\eta\left(x_{1}, x_{2}\right)\right)\right\rangle \geq r\left\|x_{1}-x_{2}\right\|^{q}, \quad \forall x_{1}, x_{2} \in X
$$


(iv) $\alpha$-Lipschitz continuous if there exists a constant $\alpha>0$ such that

$$
\left\|A\left(x_{1}\right)-A\left(x_{2}\right)\right\| \leq \alpha\left\|x_{1}-x_{2}\right\|, \quad \forall x_{1}, x_{2} \in X
$$

Definition 2.4. A set-valued mapping $S: X \rightarrow C B(X)$ is said to be

(i) $D$-Lipschitz continuous if there exists a constant $\alpha>0$ such that

$$
D(S(x), S(y)) \leq \alpha\|x-y\| \quad \forall x, y \in X
$$

where $D(\cdot, \cdot)$ is the Hausdorff metric on $C B(X)$.

(ii) $\beta$-strongly $\eta$-accretive if there exists a constant $\beta>0$ such that

$$
\left\langle u_{1}-u_{2}, J_{q}\left(\eta\left(x_{1}, y_{1}\right)\right)\right\rangle \geq \beta\left\|x_{1}-y_{1}\right\|^{q}, \quad \forall x_{1}, y_{1} \in X, u_{1} \in S\left(x_{1}\right), \quad u_{2} \in S\left(y_{1}\right) \text {. }
$$

(iii) $(\sigma, \zeta)$-relaxed cocoercive if there exist two constants $\sigma, \zeta>0$ such that

$$
\begin{array}{r}
\left\langle u_{1}-u_{2}, J_{q}\left(x_{1}-y_{1}\right)\right\rangle \geq-\sigma\left\|u_{1}-u_{2}\right\|^{q}+\zeta\left\|x_{1}-y_{1}\right\|^{q}, \\
\forall x_{1}, y_{1} \in X, \quad u_{1} \in S\left(x_{1}\right), \quad u_{2} \in S\left(y_{1}\right) .
\end{array}
$$

(iv) $\gamma_{i}$-strongly $\eta_{i}$-accretive with respect to the first argument of the mapping $F_{i}: X_{1} \times$ $X_{2} \times X_{3} \rightarrow X_{i}$, if there exists a constant $\gamma_{i}>0$ such that

$$
\begin{array}{r}
\left\langle F_{i}\left(u_{1}, \cdot, \cdot\right)-F_{i}\left(u_{2}, \cdot, \cdot\right), J_{q}\left(\eta_{i}\left(x_{1}, y_{1}\right)\right)\right\rangle \geq r_{i}\left\|x_{1}-y_{1}\right\|^{2} \\
\forall x_{1}, y_{1} \in X, \quad u_{1} \in S\left(x_{1}\right), \quad u_{2} \in S\left(y_{1}\right)
\end{array}
$$

where $i=1,2,3$.

Definition 2.5. Let $A_{i}: X_{i} \rightarrow X_{i}$ be a single-valued mapping and $S_{i}: X_{i} \rightarrow B C\left(X_{i}\right)$ be a setvalued mapping $(i=1,2,3)$. For $i=1,2,3$, a single-valued mapping $F_{i}: X_{1} \times X_{2} \times X_{3} \rightarrow X_{i}$ is said to be

(i) $\left(\mu_{i 1}, \mu_{i 2}, \mu_{i 3}\right)$-Lipschitz continuous if there exist three constants $\mu_{i 1}, \mu_{i 2}, \mu_{i 3}>0$ such that

$$
\begin{array}{r}
\left\|F_{i}\left(x_{1}, x_{2}, x_{3}\right)-F_{i}\left(y_{1}, y_{2}, y_{3}\right)\right\| \leq \mu_{i 1}\left\|x_{1}-y_{1}\right\|+\mu_{i 2}\left\|x_{2}-y_{2}\right\|+\mu_{i 3}\left\|x_{3}-y_{3}\right\| \\
\forall x_{i}, y_{i} \in X_{i} ;
\end{array}
$$

(ii) $\left(\psi_{i}, \kappa_{i}\right)$-relaxed cocoercive with respect to $A_{i} S_{i}$ in the first argument, if there exist constants $\psi_{i}, \kappa_{i}>0$ such that

$$
\begin{array}{r}
\left\langle F_{i}\left(x_{1}, \cdot, \cdot\right)-F_{i}\left(x_{2}, \cdot, \cdot\right), J_{q}\left(A_{i}\left(a_{1}\right)-A_{i}\left(b_{1}\right)\right)\right\rangle \\
\geq-\psi_{i}\left\|F_{i}\left(x_{1}, \cdot, \cdot\right)-F\left(x_{2}, \cdot \cdot\right)\right\|^{q_{i}}+\kappa_{i}\left\|x_{1}-x_{2}\right\|^{q_{i}}, \\
\forall x_{1}, x_{2} \in X_{i}, a_{1} \in S_{i}\left(x_{1}\right), b_{1} \in S_{i}\left(x_{2}\right) .
\end{array}
$$


In a similar way, we can define Lipschitz continuity and $\left(\psi_{i}, \kappa_{i}\right)$-relaxed cocoercive with respect to $A_{i} S_{i}$ of $F_{i}(\cdot, \cdot, \cdot)$ in the second, or the three argument.

Definition 2.6. Let $A: X \rightarrow X$ and $\eta: X \times X \rightarrow X$ be single-valued mappings. A set-valued mapping $M: X \times X \rightarrow 2^{X}$ is said to be

(i) accretive if

$$
\left\langle u_{1}-u_{2}, J_{q}\left(x_{1}-y_{1}\right)\right\rangle \geq 0, \quad \forall x_{1}, y_{1} \in X, u_{1} \in M\left(x_{1}, \cdot\right), u_{2} \in M\left(y_{1}, \cdot\right)
$$

(ii) $\eta$-accretive if

$$
\left\langle u_{1}-u_{2}, J_{q}\left(\eta\left(x_{1}, y_{1}\right)\right)\right\rangle \geq 0, \quad \forall x_{1}, y_{1} \in X, u_{1} \in M\left(x_{1}, \cdot\right), u_{2} \in M\left(y_{1}, \cdot\right)
$$

(iii) $m$-relaxed $\eta$-accretive, if there exists a constant $m>0$ such that

$$
\left\langle u_{1}-u_{2}, J_{q}\left(\eta\left(x_{1}, y_{1}\right)\right)\right\rangle \geq-m\left\|x_{1}-y_{1}\right\|^{q}, \quad \forall x_{1}, y_{1} \in X, u_{1} \in M\left(x_{1}, \cdot\right), u_{2} \in M\left(y_{1}, \cdot\right) ;
$$

(iv) $A$-accretive if $M$ is accretive and $(A+\rho M)(X)=X$ for all $\rho>0$;

(v) $(A, \eta)$-accretive if $M$ is $m$-relaxed $\eta$-accretive and $(A+\rho M)(X)=X$ for every $\rho>0$.

Based on [9], we can define the resolvent operator $R_{\rho, M}^{A, \eta}$ as follows.

Definition 2.7 (see [9]). Let $\eta: X \times X \rightarrow X$ be a single-valued mapping $A: X \rightarrow X$ be a strictly $\eta$-accretive single-valued mapping and $M: X \times X \rightarrow 2^{X}$ be a $(A, \eta)$-accretive mapping. The resolvent operator $R_{\rho, M}^{A, \eta}: X \rightarrow X$ is defined by

$$
R_{\rho, M}^{A, \eta}(x)=(A+\rho M)^{-1}(x) \quad \forall x \in X,
$$

where $\rho>0$ is a constant.

Remark 2.8. The $(A, \eta)$-accretive mappings are more general than $(H, \eta)$-monotone mappings, $H$-accretive mappings, $A$-monotone operators, $\eta$-subdifferential operators, and $m$ accretive mappings in Banach space or Hilbert space, and the resolvent operators associated with $(A, \eta)$-accretive mappings include as special cases the corresponding resolvent operators associated with $(H, \eta)$-monotone operators, $m$-accretive mappings, $H$-accretive mappings, $A$-monotone operators, $\eta$-subdifferential operators $[5,6,11,14,15,26,27,35-37]$.

Lemma 2.9 (see [9]). Let $\eta_{i}: X_{i} \times X_{i} \rightarrow X_{i}$ be $\tau_{i}$-Lipschtiz continuous mapping, $A_{i}: X_{i} \rightarrow X_{i}$ be an $r_{i}$-strongly $\eta_{i}$-accretive mapping, and $M_{i}: X_{i} \times X_{j} \rightarrow 2^{X_{1}}(j \equiv(1+i)$ mode 3$)$ be set-valued $\left(A_{i}, \eta_{i}\right)$-accretive mapping, respectively. Then the generalized resolvent operator $R_{\rho_{i}, M_{i}}^{A_{i}, \eta_{i}}: X_{i} \rightarrow X_{i}$ is 
$\tau_{i}^{q_{i}-1} /\left(r_{i}-m_{i} \rho_{i}\right)$-Lipschitz continuous, that is,

$$
\left\|R_{\rho_{i}, M_{i}}^{A_{i}, \eta_{i}}\left(x_{i}\right)-R_{\rho_{i}, M_{i}}^{A_{i}, \eta_{i}}\left(y_{i}\right)\right\| \leq \frac{\tau_{i}^{q_{i}-1}}{r_{i}-m_{i} \rho_{i}}\left\|x_{i}-y_{i}\right\| \quad \forall x_{i}, y_{i} \in X_{i}
$$

where $\rho_{i} \in\left(0, r_{i} / m_{i}\right), q_{i}>1$, and $i=1,2,3$.

In the study of characteristic inequalities in $q_{i}$-uniformly smooth Banach spaces $X_{i}, \mathrm{Xu}$ [29] proved the following result.

Lemma 2.10 (see [29]). Let $X_{i}$ be a real uniformly smooth Banach space. Then $X_{i}$ is $q_{i}$-uniformly smooth if andonly if there exists a constant $c_{q_{i}}>0$ such that for all $x_{i}, y_{i} \in X_{i}$

$$
\left\|x_{i}+y_{i}\right\|^{q_{i}} \leq\left\|x_{i}\right\|^{q_{i}}+q_{i}\left\langle y_{i}, J_{q_{i}}\left(x_{i}\right)\right\rangle+c_{q_{i}}\left\|y_{i}\right\|^{q_{i}} \quad(i=1,2,3) .
$$

Theorem 2.11. Let the function $g(x, y)=(x+y)^{q}-x^{q}-y^{q}$, where $x, y>0$ and $q>0$, then

$$
\begin{aligned}
& \text { (i) } g(x, y)>0, \quad \text { as } q>1 \text {, } \\
& \text { (ii) } g(x, y)=0, \quad \text { as } q=1 \text {, } \\
& \text { (iii) } g(x, y)<0, \quad \text { as } q<1 \text {. }
\end{aligned}
$$

Proof. Let $h(a, b)=a^{q}+b^{q}-1$, where $0<a, b<1, a+b=1,0<q$. Then $h(a, b)=a^{q}+(1-a)^{q}-1$ by the $b=1-a$. We can obtain

$$
\begin{gathered}
h(a, b) \geq 1-2\left(\frac{1}{2}\right)^{q}>0, \quad(\forall 1<q), \\
h(a, b) \leq 1-2\left(\frac{1}{2}\right)^{q}<0, \quad(\forall 0<q<1), \\
h(a, b)=0, \quad(q=1) .
\end{gathered}
$$

Let $a=x /(x+y)$, and $b=y /(x+y)$, where $x, y>0$. It follows that

(i) $g(x, y)=(x+y)^{q} h(a, b)>0$, as $q>1$,

(ii) $g(x, y)=(x+y)^{q} h(a, b)=0, \quad$ as $q=1$,

(iii) $g(x, y)=(x+y)^{q} h(a, b)<0$, as $q<1$.

This completes the proof.

Corollary 2.12. Let $a, b, c>0$ be real, for any real $q \geq 1$, if $a^{q} \leq b^{q}+c^{q}$, then

$$
a \leq b+c .
$$


Proof. The proof directly follows from the (i) in the Theorem 2.11.

Definition 2.13 (see [38]). Let $\widetilde{\Xi}=\left\{\left(c_{i j}\right)_{m \times n}: c_{i j} \in R\right.$ is a real $\}$ be a real matrix set, then the mappings

$$
\begin{gathered}
\left\|\left(c_{i j}\right)_{m \times n}\right\|_{q}=\left\{\sum_{i, j=1,1}^{n, m}\left|c_{i j}\right|^{q}\right\}^{1 / q}(q>0), \\
\left\|\left(c_{i j}\right)_{m \times n}\right\|_{\infty}=\max _{1 \leq i \leq n, 1 \leq j \leq m}\left|c_{i j}\right|
\end{gathered}
$$

is called the $q$-norm, and $\infty$-norm, respectively.

Obviously, $(\widetilde{\Xi},\|\cdot\|)$ may be a Banach space on real field $R$, which is called the real matrixBanach space.

Definition 2.14 (see [38]). Let $\widetilde{\Xi}=\left\{\left(c_{i j}\right)_{m \times n}: c_{i j} \in R\right.$ is a real $\}$ be a real matrix-Banach Space with the matrix-norm $\|\cdot\|\left(\|\cdot\|=\|\cdot\|_{q}(q>0)\right.$, or $\left.\|\cdot\|_{\infty}\right)$. If

$$
\left(\lim _{k \rightarrow \infty} c_{i j}(k)\right)_{m \times n}=\left(d_{i j}\right)_{m \times n} \in \widetilde{\Xi},
$$

then the matrix $\left(d_{i j}\right)_{m \times n}$ is called the limit matrix of matrix sequence $\left\{\left(c_{i j}(k)\right)_{m \times n}\right\}$, noted by $\lim _{k \rightarrow \infty}\left(c_{i j}(k)\right)_{m \times n}=\left(d_{i j}\right)_{m \times n}$, where $\left\{c_{i j}(k)\right\}$ is a real sequence, $\lim _{k \rightarrow \infty} c_{i j}(k)=d_{i j}, m, n, i, j=$ $1,2, \ldots$, and $i \leq m, j \leq n$.

Lemma 2.15 (see [38]). $\lim _{k \rightarrow \infty}\left(c_{i j}(k)\right)_{m \times n}=\left(d_{i j}\right)_{m \times n}$ if and only if

$$
\lim _{k \rightarrow \infty}\left\|\left(c_{i j}(k)\right)_{m \times n}-\left(d_{i j}\right)_{m \times n}\right\|=0 .
$$

Hence, if $\lim _{k \rightarrow \infty}\left(c_{i j}(k)\right)_{m \times n}=\left(d_{i j}\right)_{m \times n}$, then $\lim _{k \rightarrow \infty}\left\|\left(c_{i j}(k)\right)_{m \times n}\right\|=\left\|\left(d_{i j}\right)_{m \times n}\right\|$.

In this paper, the matrix norm symbol $\|\cdot\|_{1}$ is noted by $\|\cdot\|$.

Definition 2.16. Let $a_{i}, b_{i}(i=1, \cdot, \cdot, \cdot, n)$ be real numbers, and $\vec{a}=\left(a_{1}, \cdot, \cdot, \cdot, a_{n}\right)^{T}$ and $\vec{b}=$ $\left(b_{1}, \cdot, \cdot, \cdot, b_{n}\right)^{T}$ be two real vectors, then $\vec{a}=\left(a_{1}, \cdot, \cdot, \cdot, a_{n}\right)^{T} \leq \vec{b}=\left(b_{1}, \cdot, \cdot, \cdot, b_{n}\right)^{T}$ if and only if $a_{i} \leq b_{i}(i=1, \cdot, \cdot, \cdot, n)$.

\section{Quasi-Variational Inclusions System Problem and Hybrid Proximal Point Algorithm}

Let $X_{i}$ be a real $q_{i}$-uniformly smooth Banach space with dual space $X_{i}^{*},\langle\cdot, \cdot\rangle$ be the dual pair between $X_{i}$ and $X_{i}^{*}, 2^{X_{i}}$ denote the family of all the nonempty subsets of $X_{i}$, and $C B\left(X_{i}\right)$ 
denote the family of all nonempty closed bounded subsets of $X_{i}$. The generalized duality mapping $J_{q_{i}}: X_{i} \rightarrow 2^{X_{i}^{*}}$ is defined by

$$
J_{q_{i}}(x)=\left\{f_{i}^{*} \in X_{i}^{*}:\left\langle x, f_{i}^{*}\right\rangle=\|x\|^{q_{i}},\left\|f^{*}\right\|=\|x\|^{q_{i}-1}\right\}, \quad \forall x \in X_{i}
$$

where $q_{i}>1$ is a constant. Now, we consider the following generational nonlinear set-valued quasi-variational inclusions system problem with $(A, \eta)$-accretive mappings (GNSVQVIS) problem.

Let $A_{i}: X_{i} \rightarrow X_{i}, \eta_{i}: X_{i} \times X_{i} \rightarrow X_{i}$, and $F_{i}, G_{i}: X_{1} \times X_{2} \times X_{3} \rightarrow X_{i}$ be single-valued mappings for $i=1,2,3$. Let $M_{i}: X_{i} \times X_{j} \rightarrow 2^{X_{1}}(j \equiv(1+i)$ mode 3$)$ be a set-valued $\left(A_{i}, \eta_{i}\right)$ accretive mapping and $S_{i}, T_{i}, U_{i}, V_{i}: X_{i} \rightarrow C B\left(X_{i}\right)$ be set-valued mappings for $i=1,2,3$.

For any $\varepsilon_{i} \in X_{i}$, finding $\left(x_{i}, a_{i}, b_{i}, c_{i}, d_{i}\right)$ such that $\left(x_{1}, x_{2}, x_{3}\right) \in X_{1} \times X_{2} \times X_{3}, a_{i} \in S_{i}\left(x_{i}\right)$, $b_{i} \in T_{i}\left(x_{i}\right), c_{i} \in U_{i}\left(x_{i}\right), d_{i} \in V_{i}\left(x_{i}\right)$, and

$$
\begin{aligned}
& \varepsilon_{1} \in F_{1}\left(x_{1}, x_{2}, x_{3}\right)-G_{1}\left(a_{1}, a_{2}, a_{3}\right)+M_{1}\left(d_{1}, d_{2}\right), \\
& \varepsilon_{2} \in F_{2}\left(x_{1}, x_{2}, x_{3}\right)-G_{2}\left(b_{1}, b_{2}, b_{3}\right)+M_{2}\left(d_{2}, d_{3}\right), \\
& \varepsilon_{3} \in F_{3}\left(x_{1}, x_{2}, x_{3}\right)-G_{3}\left(c_{1}, c_{2}, c_{3}\right)+M_{3}\left(d_{3}, d_{1}\right),
\end{aligned}
$$

where $i=1,2,3$.

Remark 3.1. Some special cases of problem (3.2) are as follows.

(i) If $G_{i} \equiv 0, M_{i}(\cdot, \cdot) \equiv M_{i}(\cdot), V_{i} \equiv g_{i}, A_{i} \equiv H_{i}, \varepsilon_{i}=0$ and $X_{i}$ is a Hilbert space, then the problem (3.2) reduces to the problem associated with the system of variational inclusions with $\left(H_{i}, \eta_{i}\right)$-monotone operators, which is finding $(x, y, z, a, b, c, d, e, p, q, u, v)$ such that $(x, y, z) \in \mathrm{H}_{1} \times \mathrm{H}_{2} \times \mathrm{H}_{3}, a \in A(x)=S_{1}, b \in B(y)=S_{2}, c \in C(z)=S_{3}, d \in D(x)=T_{1}$, $e \in E(y)=T_{2}, p \in P(z)=T_{3}, q \in Q(x)=U_{1}, u \in U(y)=U_{2}, v \in V(z)=U_{3}$ and

$$
\begin{aligned}
& 0 \in F_{1}(x, y, z)-G_{1}(a, b, c)+M_{1}\left(g_{1}(x)\right), \\
& 0 \in F_{2}(x, y, z)-G_{2}(d, e, p)+M_{2}\left(g_{2}(y)\right), \\
& 0 \in F_{3}(x, y, z)-G_{3}(q, u, v)+M_{3}\left(g_{3}(z)\right),
\end{aligned}
$$

where $i=1,2,3$.

Problem (3.3) contains the system of variational inclusions with $(H, \eta)$-monotone operators in Peng and Zhu [14], and the system of variational inclusions with $(H, \eta)$ monotone operators in [8] as special cases.

(ii) If $G_{i} \equiv 0, \varepsilon_{i}=0, X_{i} \equiv \mathrm{H}_{i}$ (Hilbert space) and, $M_{i}(\cdot, \cdot) \equiv M_{i}(\cdot) \equiv \Delta_{\eta_{i}} \varphi_{i}(\cdot)$, where $\varphi_{i}: \mathrm{H}_{i} \rightarrow R \cup \infty$ is a proper, $\eta_{i}$-subdifferentiable functional and $\Delta_{\eta_{i}} \varphi_{i}$ denotes the $\eta_{i}$-subdifferential operator of $\varphi_{i}$, then problem(3.3) changes to the problem associated with 
the following system of variational-like inequalities, which is finding $(x, y, z) \in \mathrm{H}_{1} \times \mathrm{H}_{2} \times \mathrm{H}_{3}$ such that

$$
\begin{array}{ll}
\left\langle F_{1}(x, y, z), \eta_{1}(a, x)\right\rangle+\varphi_{1}(a)-\varphi_{1}(x) \geq 0, & \forall a \in \mathrm{H}_{1}, \\
\left\langle F_{2}(x, y, z), \eta_{2}(b, x)\right\rangle+\varphi_{2}(b)-\varphi_{2}(x) \geq 0, & \forall b \in \mathrm{H}_{2}, \\
\left\langle F_{3}(x, y, z), \eta_{3}(c, x)\right\rangle+\varphi_{3}(c)-\varphi_{3}(x) \geq 0, & \forall c \in \mathrm{H}_{3},
\end{array}
$$

where $i=1,2,3$.

(iii) If $G_{i} \equiv 0, \eta_{i}\left(x_{i}, y_{i}\right)=x_{i}-y_{i}, \varepsilon_{i}=0, X_{i} \equiv \mathrm{H}_{i}$ (Hilbert space) and $M_{i}(\cdot, \cdot) \equiv M_{i}(\cdot) \equiv$ $\partial \varphi_{i}(\cdot)$, where $\varphi_{i}: \mathrm{H}_{i} \rightarrow R \cup \infty$ is a proper, convex, lower semicontinuous functional and $\partial \varphi_{i}(\cdot)$ denotes the subdifferential operator of $\varphi_{i}(\cdot)$, then problem (3.3) changes to the problem associated with the following system of variational inequalities, which is finding $(x, y, z) \in$ $\mathrm{H}_{1} \times \mathrm{H}_{2} \times \mathrm{H}_{3}$ such that

$$
\begin{array}{ll}
\left\langle F_{1}(x, y, z),(a-x)\right\rangle+\varphi_{1}(a)-\varphi_{1}(x) \geq 0, & \forall a \in \mathrm{H}_{1} \\
\left\langle F_{2}(x, y, z),(b-x)\right\rangle+\varphi_{2}(b)-\varphi_{2}(x) \geq 0, & \forall b \in \mathrm{H}_{2} \\
\left\langle F_{3}(x, y, z),(c-x)\right\rangle+\varphi_{3}(c)-\varphi_{3}(x) \geq 0, & \forall c \in \mathrm{H}_{3}
\end{array}
$$

where $i=1,2,3$.

(iv) If $\varepsilon_{i}=0, X_{i} \equiv \mathrm{H}_{i}$ (Hilbert space), and $M_{i}(\cdot, \cdot) \equiv M_{i}(\cdot) \equiv \partial \delta_{K_{i}}(\cdot)$, where $K_{i} \subset \mathrm{H}_{i}$ is a nonempty, closed, and convex subsets and $\delta_{K_{i}}$ denotes the indicator of $K_{i}$, then problem (3.5) reduces to the problem associated with the following system of variational inequalities, which is finding $(x, y, z) \in \mathrm{H}_{1} \times \mathrm{H}_{2} \times \mathrm{H}_{3}$ such that

$$
\begin{aligned}
& \left\langle F_{1}(x, y, z),(a-x)\right\rangle \geq 0, \quad \forall a \in K_{1}, \\
& \left\langle F_{2}(x, y, z),(b-x)\right\rangle \geq 0, \quad \forall b \in K_{2}, \\
& \left\langle F_{3}(x, y, z),(c-x)\right\rangle \geq 0, \quad \forall c \in K_{3},
\end{aligned}
$$

where $i=1,2,3$.

(v) If $\varepsilon_{i}=0$, and $\mathrm{H}_{i}=\mathrm{H}$ is a Hilbert space, $K_{i}=K$ is a nonempty, closed and convex subset, for all $x_{i} \in K, F_{i}\left(x_{1}, x_{2}, x_{3}\right)=\sigma_{i} T(y, x)+x_{i}-x_{i+1}(i+1 \equiv n \bmod (3), n=1,2,3, \cdot, \cdot, \cdot)$, where $T: K \times K \rightarrow H$ is a mapping on $K \times K, \sigma_{i}>0$ is a constant, then problem (3.6) changes to the following problem: find $x_{i} \in K$ such that

$$
\begin{array}{ll}
\left\langle\sigma_{1} T\left(x_{2}, x\right)+x_{1}-x_{2},\left(a-x_{1}\right)\right\rangle \geq 0, & \forall a \in K, \\
\left\langle\sigma_{2} T\left(x_{3}, x\right)+x_{2}-x_{3},\left(b-x_{2}\right)\right\rangle \geq 0, & \forall b \in K, \\
\left\langle\sigma_{3} T\left(x_{1}, x\right)+x_{3}-x_{1},\left(c-x_{3}\right)\right\rangle \geq 0, & \forall c \in K,
\end{array}
$$

where $i=1,2,3$.

Moreover, if $\sigma_{3}=0$, problem (3.7) becomes the problem introduced and studied by Verma [31]. 
We can see that problem (3.2) includes a number of known classes of system of variational inequalities and variational inclusions as special cases (see, e.g., [2-9, 11-27, 29, 32-37]). It is worth noting that problems (3.2)-(3.7) are all new mathematical models.

Theorem 3.2. Let $X_{i}$ be a Banach space, $\eta_{i}: X_{i} \times X_{i} \rightarrow X_{i}$ be $\tau_{i}$-Lipschtiz continuous mapping, $A_{i}: X_{i} \rightarrow X_{i}$ be an $r_{i}$-strongly $\eta_{i}$-accretive mapping, and $M_{i}: X_{i} \times X_{j} \rightarrow 2^{X_{1}}(j \equiv(1+i)$ mode 3$)$ be a set-valued $\left(A_{i}, \eta_{i}\right)$-accretive mapping for $i=1,2,3$. Then the following statements are mutually equivalent.

(i) An element $\left(x_{i}, a_{i}, b_{i}, c_{i}, d_{i}\right)$ is a solution of problem (3.2), $i=1,2,3$.

(ii) For $\left(x_{1}, x_{2}, x_{3}\right) \in X_{1} \times X_{2} \times X_{3}$ and $a_{i} \in S_{i}\left(x_{i}\right), b_{i} \in T_{i}\left(x_{i}\right), c_{i} \in U_{i}\left(x_{i}\right), d_{i} \in V_{i}\left(x_{i}\right)$, the following relations hold:

$$
\begin{aligned}
& d_{1}=R_{\rho_{1}, M_{1}\left(d_{1,}\right)}^{A_{1}, \eta_{1}}\left(A_{1}\left(d_{1}\right)+\rho_{1} \varepsilon_{1}+\rho_{1} G_{1}\left(a_{1}, a_{2}, a_{3}\right)-\rho_{1} F_{1}\left(x_{1}, x_{2}, x_{3}\right)\right), \\
& d_{2}=R_{\rho_{2}, M_{1}\left(d_{2},\right)}^{A_{2}, \eta_{2}}\left(A_{1}\left(d_{2}\right)+\rho_{2} \varepsilon_{2}+\rho_{2} G_{2}\left(b_{1}, b_{2}, b_{3}\right)-\rho_{2} F_{2}\left(x_{1}, x_{2}, x_{3}\right)\right), \\
& d_{3}=R_{\rho_{3}, M_{3}\left(d_{3,}\right)}^{A_{3}, \eta_{3}}\left(A_{3}\left(d_{3}\right)+\rho_{3} \varepsilon_{3}+\rho_{3} G_{3}\left(c_{1}, c_{2}, c_{3}\right)-\rho_{3} F_{3}\left(x_{1}, x_{2}, x_{3}\right)\right),
\end{aligned}
$$

where $\rho_{i}>0$ is a constant and $i=1,2,3$, respectively.

Proof. This directly follows from definition of $R_{\rho_{i}, M_{i}(,)}^{A_{i}, \eta_{i}}$ and the problem (3.2) for $i=1,2,3$.

Algorithm 3.3. Let $\left\{\alpha_{i}^{n}\right\}_{n=0}^{\infty},\left\{\xi_{i}^{n}\right\}_{n=0}^{\infty}$ and $\left\{\rho_{i}^{n}\right\}_{n=0}^{\infty}$ be three nonnegative sequences such that

$$
\lim _{n \rightarrow \infty} \xi_{i}^{n}=0, \quad \alpha=\limsup _{n \rightarrow \infty} \alpha_{i}^{n}<1, \quad \rho_{i}^{n} \uparrow \rho_{i} \leq \infty \quad(n=0,1,2, \ldots ; i=1,2,3) .
$$

Step 1. For arbitrarily chosen initial points $x_{i}^{0} \in X_{i}, a_{i}^{0} \in S_{i}\left(x_{i}^{0}\right), b_{i}^{0} \in T_{i}\left(x_{i}^{0}\right), c_{i}^{0} \in U_{i}\left(x_{i}^{0}\right)$, $d_{i}^{0} \in V_{i}\left(x_{i}^{0}\right), y_{i}^{0} \in X_{i}(1 \leq i \leq 3)$, Set

$$
\begin{gathered}
x_{i}^{1}=\left(1-\alpha_{i}^{0}\right) x_{i}^{0}+\alpha_{i}^{0}\left(x_{i}^{0}-d_{i}^{0}+y_{i}^{0}\right), \\
\Omega_{i}^{1}=A_{i}\left(d_{i}^{0}\right)+\rho_{i}^{0} \varepsilon_{i}+\rho_{i}^{0} G_{i}\left(a_{1}^{0}, a_{2}^{0}, a_{3}^{0}\right)-\rho_{i}^{0} F_{i}\left(x_{1}^{0}, x_{2}^{0}, x_{3}^{0}\right),
\end{gathered}
$$

where the $y_{i}^{0}$ satisfies

$$
\left\|y_{i}^{0}-R_{\rho_{1}, M_{1}\left(d_{1},\right)}^{A_{1}, \eta_{1}}\left(\Omega_{i}^{1}\right)\right\| \leq \xi_{i}^{0}\left\|y_{i}^{0}-d_{i}^{0}\right\|
$$


By using [39], we can choose suitable $a_{i}^{1} \in S_{i}\left(x_{i}^{1}\right), b_{i}^{1} \in T_{i}\left(x_{i}^{1}\right), c_{i}^{1} \in U_{i}\left(x_{i}^{1}\right)$ and $d_{i}^{1} \in V_{i}\left(x_{i}^{1}\right)$ such that

$$
\begin{aligned}
& \left\|a_{i}^{0}-a_{i}^{1}\right\| \leq\left(1+\frac{1}{1}\right) D\left(S_{i}\left(x_{i}^{0}\right), S_{i}\left(x_{i}^{1}\right)\right), \\
& \left\|b_{i}^{0}-b_{i}^{1}\right\| \leq\left(1+\frac{1}{1}\right) D\left(T_{i}\left(x_{i}^{0}\right), T_{i}\left(x_{i}^{1}\right)\right), \\
& \left\|c_{i}^{0}-c_{i}^{1}\right\| \leq\left(1+\frac{1}{1}\right) D\left(U_{i}\left(x_{i}^{0}\right), U_{i}\left(x_{i}^{1}\right)\right), \\
& \left\|d_{i}^{0}-d_{i}^{1}\right\| \leq\left(1+\frac{1}{1}\right) D\left(V_{i}\left(x_{i}^{0}\right), V_{i}\left(x_{i}^{1}\right)\right)
\end{aligned}
$$

for $i=1,2,3$.

Step 2. The sequences $\left\{x_{i}^{n}\right\}_{n=0}^{\infty},\left\{a_{i}^{n}\right\}_{n=0}^{\infty},\left\{b_{i}^{n}\right\}_{n=0}^{\infty},\left\{c_{i}^{n}\right\}_{n=0}^{\infty}$, and $\left\{d_{i}^{n}\right\}_{n=0}^{\infty}$ are generated by an iterative procedure:

$$
\begin{gathered}
x_{i}^{n+1}=\left(1-\alpha_{i}^{n}\right) x_{i}^{n}+\alpha_{i}^{n}\left(x_{i}^{n}-d_{i}^{n}+y_{i}^{n}\right), \\
\Omega_{i}^{n+1}=A_{i}\left(d_{i}^{n}\right)+\rho_{i}^{n} \varepsilon_{i}+\rho_{i}^{n} G_{i}\left(a_{1}^{n}, a_{2}^{n}, a_{3}^{n}\right)-\rho_{i}^{n} F_{i}\left(x_{1}^{n}, x_{2}^{n}, x_{3}^{n}\right),
\end{gathered}
$$

where

$$
\left\|y_{i}^{n}-R_{\rho_{i}, M_{i}\left(d_{i},\right)}^{A_{i}, \eta_{i}}\left(\Omega_{i}^{n}\right)\right\| \leq \xi_{i}^{n}\left\|y_{i}^{n}-d_{i}^{n}\right\|
$$

Thus, we can choose suitable $a_{i}^{n+1} \in S_{i}\left(x_{i}^{1}\right), b_{i}^{n+1} \in T_{i}\left(x_{i}^{n}\right), c_{i}^{n+1} \in U_{i}\left(x_{i}^{n}\right)$ and $d_{i}^{n+1} \in V_{i}\left(x_{i}^{n}\right)$ such that

$$
\begin{aligned}
\left\|a_{i}^{n}-a_{i}^{n+1}\right\| & \leq\left(1+\frac{1}{n+1}\right) D\left(S_{i}\left(x_{i}^{n}\right), S_{i}\left(x_{i}^{n+1}\right)\right), \\
\left\|b_{i}^{n}-b_{i}^{n+1}\right\| & \leq\left(1+\frac{1}{n+1}\right) D\left(T_{i}\left(x_{i}^{n}\right), T_{i}\left(x_{i}^{n+1}\right)\right), \\
\left\|c_{i}^{n}-c_{i}^{n+1}\right\| & \leq\left(1+\frac{1}{n+1}\right) D\left(U_{i}\left(x_{i}^{n}\right), U_{i}\left(x_{i}^{n+1}\right)\right), \\
\left\|d_{i}^{n}-d_{i}^{n+1}\right\| & \leq\left(1+\frac{1}{n+1}\right) D\left(V_{i}\left(x_{i}^{n}\right), V_{i}\left(x_{i}^{n+1}\right)\right)
\end{aligned}
$$

for $i=1,2,3$ and $n=0,1,2, \ldots$

Remark 3.4. If we choose suitable some operators $A_{i}, \eta_{i}, F_{i}, G_{i}, S_{i}, T_{i}, \mathrm{U}_{i}, V_{i}, M_{i}, \varepsilon_{i}$, and space $X_{i}$, then Algorithm 3.3 can be degenerated to a number of known algorithms for solving the system of variational inequalities and variational inclusions (see, e.g., [2-9, 11-27, 29, 31$35,38,39])$. 


\section{Existence and Convergence}

In this section, we prove the existence of solutions for problem (3.2) and the convergence of iterative sequences generated by Algorithm 3.3.

Theorem 4.1. Let $X_{i}$ be a $q_{i}$-uniformly smooth Banach space, $\eta_{i}: X_{i} \times X_{i} \rightarrow X_{i}$ be a $\tau_{i}$-Lipschtiz continuous mapping, and $A_{i}: X_{i} \rightarrow X_{i}$ be a $r_{i}$-strongly $\eta_{i}$-accretive mapping and $\gamma_{i}$-Lipschitz continuous. Let $S_{i}, T_{i}, U_{i}, V_{i}: X_{i} \rightarrow C B\left(X_{i}\right)$ be a set-valued mappings of D-Lipschitz continuous with constants $s_{i}, t_{i} \cdot u_{i}, v_{i}$, and $S_{i}, T_{i}, U_{i}, V_{i}$ be $\left(\sigma_{i}, \zeta_{i}\right)$-relaxed cocoercive, respectively. Let $F_{i}: X_{1} \times$ $X_{2} \times X_{3} \rightarrow X_{i}$ be Lipschitz continuous with constants $\left(\mu_{i 1}, \mu_{i 2}, \mu_{i 3}\right)$ and $\left\|F_{i}\left(x_{1}, x_{2}, x_{3}\right)\right\| \leq h_{i}\left(h_{i} \geq\right.$ $0)$ for all $\left(x_{1}, x_{2}, x_{3}\right) \in\left(X_{1} \times X_{2} \times X_{3}\right)$, and $\left(\psi_{i}, \kappa_{i}\right)$-relaxed cocoercive with respect to $A_{i} S_{i}$ in the first, second and third arguments, respectively. Let $G_{i}: X_{1} \times X_{2} \times X_{3} \rightarrow X_{i}$ be Lipschitz continuous with constants $\left(v_{i 1}, v_{i 2}, v_{i 3}\right)$ and $\left\|G_{i}\left(x_{1}, x_{2}, x_{3}\right)\right\| \leq g_{i}\left(g_{i} \geq 0\right)$ for all $\left(x_{1}, x_{2}, x_{3}\right) \in X_{1} \times X_{2} \times X_{3}$. Let $M_{1}: X_{1} \times X_{2} \rightarrow 2^{X_{1}}, M_{2}: X_{2} \times X_{3} \rightarrow 2^{X_{2}}, M_{3}: X_{3} \times X_{1} \rightarrow 2^{X_{3}}$ be some set-valued mappings such that for each given $\left(x_{1}, x_{2}, x_{3}\right) \in X_{1} \times X_{2} \times X_{3}$, range $\left(V_{1}\right) \cap \operatorname{dom} M_{1}\left(\cdot, x_{2}\right) \neq \emptyset$, range $\left(V_{2}\right) \cap \operatorname{dom} M_{2}\left(\cdot, x_{3}\right) \neq \emptyset$, range $\left(V_{3}\right) \cap \operatorname{dom} M_{3}\left(\cdot, x_{1}\right) \neq \emptyset$ and $M_{i}: X_{i} \times X_{j} \rightarrow 2^{X_{1}}(j \equiv$ $(1+i)$ mode 3$)$ be an $\left(A_{i}, \eta_{i}\right)$-accretive mapping, respectively. Suppose that $\left\{\alpha_{i}^{n}\right\}_{n=0}^{\infty},\left\{\xi_{i}^{n}\right\}_{n=0}^{\infty}$ and $\left\{\rho_{i}^{n}\right\}_{n=0}^{\infty}$ are three nonnegative sequences with

$$
\begin{gathered}
\lim _{n \rightarrow \infty} \xi_{i}^{n}=0, \quad \alpha=\limsup _{n \rightarrow \infty} \alpha_{i}^{n}<1, \quad \rho_{i}=\lim _{n \rightarrow \infty} \rho_{i}^{n} \leq \infty \\
\left(1+q_{1} \sigma_{1} v_{1}^{q_{1}}-q_{1} \zeta_{1}+c_{q_{1}} v_{1}^{q_{1}}\right)^{1 / q_{1}}-\lambda_{1}+\rho_{1} v_{11} s_{1}<1 \\
\alpha_{1} \rho_{1}\left(\mu_{12}+v_{12} s_{2}+\mu_{13}+\nu_{13} s_{3}\right)<1 \\
\left(1+q_{2} \sigma_{2} v_{2}^{q_{2}}-q_{2} \zeta_{2}+c_{q_{2}} v_{2}^{q_{2}}\right)^{1 / q_{2}}-\lambda_{2}+\rho_{2} v_{22} t_{2}<1 \\
\alpha_{2} \rho_{2}\left(\mu_{21}+v_{21} t_{1}+\mu_{23}+\nu_{23} t_{3}\right)<1 \\
\left(1+q_{3} \sigma_{3} v_{3}^{q_{3}}-q_{3} \zeta_{3}+c_{q_{3}} v_{3}^{q_{3}}\right)^{1 / q_{3}}-\lambda_{3}+\rho_{3} v_{33} u_{3}<1 \\
\alpha_{3} \rho_{3}\left(\mu_{31}+v_{31} u_{1}+\mu_{32}+\nu_{32} u_{2}\right)<1 \\
\lambda_{i}=\frac{\tau_{i}^{q_{i}-1}}{r_{i}-m_{i} \rho_{i}}\left(c_{q_{i}} \rho_{i}^{q_{i}} \mu_{i i}^{q_{i}}+\gamma_{i}^{q_{i}} v_{i}^{q_{i}}+q_{i} \rho_{i} \psi_{i} \mu_{i i}^{q_{i}}-\rho_{i} \mathcal{\kappa}_{i}\right)^{1 / q_{i}}
\end{gathered}
$$

where $c_{q_{i}}>0$ is the same as in Lemma 2.10, $\rho_{i} \in\left(0, r_{i} / m_{i}\right)$, and $i=1,2,3$. Then the problem (3.2) has a solution $\left(x_{i}^{*}, a_{i}^{*}, b_{i}^{*}, c_{i}^{*}, d_{i}^{*}\right)(i=1,2,3)$.

Proof. Let

$$
\Omega_{i}^{n+1}=A_{i}\left(d_{i}^{n}\right)+\rho_{i}^{n} \varepsilon_{i}+\rho_{i}^{n} G_{i}\left(a_{1}^{n}, a_{2}^{n}, a_{3}^{n}\right)-\rho_{i}^{n} F_{i}\left(x_{1}^{n}, x_{2}^{n}, x_{3}^{n}\right)
$$

for $i=1,2,3$. Then it follows from (3.13) that

$$
\left\|x_{1}^{n+1}-x_{1}^{n}\right\| \leq\left(1-\alpha_{1}^{n}\right)\left\|x_{1}^{n}-x_{1}^{n-1}\right\|+\alpha_{1}^{n}\left\|x_{1}^{n}-x_{1}^{n-1}-\left(d_{1}^{n}-d_{1}^{n-1}\right)\right\|+\alpha_{1}^{n}\left\|y_{1}^{n}-y_{1}^{n-1}\right\| .
$$


Fixed Point Theory and Applications

Since $V_{1}: X_{1} \rightarrow C B\left(X_{1}\right)$ is $D$-Lipschitz continuous with constants $v_{1}$ and $\left(\sigma_{1}, \zeta_{1}\right)$-relaxed cocoercive,

$$
\begin{aligned}
\| x_{1}^{n}- & x_{1}^{n-1}-\left(d_{1}^{n}-d_{1}^{n-1}\right) \|^{q_{1}} \\
& =\left\|x_{1}^{n}-x_{1}^{n-1}\right\|^{q_{1}}-q_{1}\left\langle x_{1}^{n}-x_{1}^{n-1}, J_{q_{1}}\left(d_{1}^{n}-d_{1}^{n-1}\right)\right\rangle+c_{q_{1}}\left\|d_{1}^{n}-d_{1}^{n-1}\right\|^{q_{1}} \\
& \leq\left(1+q_{1} \sigma_{1}\left(1+\frac{1}{n+1}\right)^{q_{1}} v_{1}^{q_{1}}-q_{1} \zeta_{1}+c_{q_{1}}\left(1+\frac{1}{n+1}\right)^{q_{1}} v_{1}^{q_{1}}\right)\left\|x_{1}^{n}-x_{1}^{n-1}\right\|^{q_{1}} .
\end{aligned}
$$

By (3.15), we have

$$
\begin{aligned}
\left\|y_{1}^{n}-y_{1}^{n-1}\right\| \leq & \left\|y_{1}^{n}-R_{\rho_{1}^{n}, M_{1}\left(d_{1},\right)}^{A_{1}, \eta_{1}}\left(\Omega_{1}^{n}\right)\right\|+\left\|R_{\rho_{1}^{n}, M_{1}\left(d_{1}, \cdot\right)}^{A_{1}, \eta_{1}}\left(\Omega_{1}^{n-1}\right)-y_{1}^{n-1}\right\| \\
& +\left\|R_{\rho_{1}^{n}, M_{1}\left(d_{1},\right)}^{A_{1}, \eta_{1}}\left(\Omega_{1}^{n}\right)-R_{\rho_{1}^{n}, M_{1}\left(d_{1, \cdot}\right)}^{A_{1}, \eta_{1}}\left(\Omega_{1}^{n-1}\right)\right\| \\
\leq & \xi_{1}^{n}\left\|y_{1}^{n}-d_{1}^{n}\right\|+\xi_{1}^{n-1}\left\|y_{1}^{n-1}-d_{1}^{n-1}\right\| \\
& +\left\|R_{\rho_{1}^{n}, M_{1}\left(d_{1},\right)}^{A_{1}, \eta_{1}}\left(\Omega_{1}^{n}\right)-R_{\rho_{1}^{n}, M_{1}\left(d_{1, \cdot}\right)}^{A_{1}, \eta_{1}}\left(\Omega_{1}^{n-1}\right)\right\| .
\end{aligned}
$$

Since $\left\|F_{1}\left(x_{1}, x_{2}, x_{3}\right)\right\| \leq h_{1}$ and $\left\|G_{1}\left(x_{1}, x_{2}, x_{3}\right)\right\| \leq g_{1}$, by Lemma 2.9, we have

$$
\begin{aligned}
& \left\|R_{\rho_{1}^{n}, M_{1}\left(d_{1},\right)}^{A_{1}, \eta_{1}}\left(\Omega_{1}^{n}\right)-R_{\rho_{1}^{n}, M_{1}\left(d_{1},\right)}^{A_{1}, \eta_{1}}\left(\Omega_{1}^{n-1}\right)\right\| \\
& \leq \frac{\tau_{1}^{q_{1}-1}}{r_{1}-m_{1} \rho_{1}^{n}}\left\|\Omega_{1}^{n}-\Omega_{1}^{n-1}\right\| \\
& \leq \frac{\tau_{1}^{q_{1}-1}}{r_{1}-m_{1} \rho_{1}^{n}}\left[\left\|A_{1}\left(d_{1}^{n}\right)-A_{1}\left(d_{1}^{n-1}\right)-\rho_{1}^{n}\left(F_{1}\left(x_{1}^{n}, x_{2}^{n}, x_{3}^{n}\right)-F_{1}\left(x_{1}^{n-1}, x_{2}^{n-1}, x_{3}^{n-1}\right)\right)\right\|\right. \\
& \left.\quad+\rho_{1}^{n}\left\|G_{1}\left(a_{1}^{n}, a_{2}^{n}, a_{3}^{n}\right)-G_{1}\left(a_{1}^{n-1}, a_{2}^{n-1}, a_{3}^{n-1}\right)\right\|+\left|\rho_{1}^{n}-\rho_{1}^{n-1}\right|\left(h_{1}+g_{1}+\left\|\varepsilon_{1}\right\|\right)\right] . \\
& \leq \frac{\tau_{1}^{q_{1}-1}}{r_{1}-m_{1} \rho_{1}^{n}}\left[\left\|A_{1}\left(d_{1}^{n}\right)-A_{1}\left(d_{1}^{n-1}\right)-\rho_{1}^{n}\left(F_{1}\left(x_{1}^{n}, x_{2}^{n}, x_{3}^{n}\right)-F_{1}\left(x_{1}^{n-1}, x_{2}^{n}, x_{3}^{n}\right)\right)\right\|\right. \\
& \quad+\rho_{1}^{n}\left\|F_{1}\left(x_{1}^{n-1}, x_{2}^{n}, x_{3}^{n}\right)-F_{1}\left(x_{1}^{n-1}, x_{2}^{n-1}, x_{3}^{n}\right)\right\| \\
& \quad+\rho_{1}^{n}\left\|F_{1}\left(x_{1}^{n-1}, x_{2}^{n-1}, x_{3}^{n}\right)-F_{1}\left(x_{1}^{n-1}, x_{2}^{n-1}, x_{3}^{n-1}\right)\right\| \\
& \left.+\rho_{1}^{n}\left\|G_{1}\left(a_{1}^{n}, a_{2}^{n}, a_{3}^{n}\right)-G_{1}\left(a_{1}^{n-1}, a_{2}^{n-1}, a_{3}^{n-1}\right)\right\|\right] .
\end{aligned}
$$


Since $F_{1}: X_{1} \times X_{2} \times X_{3} \rightarrow X_{1}$ is Lipschitz continuous with constants $\mu_{11}, \mu_{12}, \mu_{13}$, and $\left(\psi_{1}, \kappa_{1}\right)$ relaxed cocoercive with respect to $A_{1} S_{1}$ in the first arguments, $G_{i}: X_{1} \times X_{2} \times X_{3} \rightarrow X_{i}$ be Lipschitz continuous with constants $\left(v_{i 1}, v_{i 2}, v_{i 3}\right)$, respectively, Lemma 2.10, we have

$$
\begin{aligned}
& \left\|A_{1}\left(d_{1}^{n}\right)-A_{1}\left(d_{1}^{n-1}\right)-\rho_{1}^{n}\left(F_{1}\left(x_{1}^{n}, x_{2}^{n}, x_{3}^{n}\right)-F_{1}\left(x_{1}^{n-1}, x_{2}^{n}, x_{3}^{n}\right)\right)\right\|^{q_{1}} \\
& \leq c_{q_{1}}\left(\rho^{n}\right)_{1}^{q_{1}}\left\|F_{1}\left(x_{1}^{n}, x_{2}^{n}, x_{3}^{n}\right)-F_{1}\left(x_{1}^{n-1}, x_{2}^{n}, x_{3}^{n}\right)\right\|^{q_{1}}+\left\|A_{1}\left(d_{1}^{n}\right)-A_{1}\left(d_{1}^{n-1}\right)\right\|^{q_{1}} \\
& \quad-q_{1} \rho_{1}^{n}\left\langle F_{1}\left(x_{1}^{n}, x_{2}^{n}, x_{3}^{n}\right)-F_{1}\left(x_{1}^{n-1}, x_{2}^{n}, x_{3}^{n}\right), J_{q}\left(A_{1}\left(d_{1}^{n}\right)-A_{1}\left(d_{1}^{n-1}\right)\right)\right\rangle \\
& \leq c_{q_{1}}\left(\rho^{n}\right)_{1}^{q_{1}}\left\|F_{1}\left(x_{1}^{n}, x_{2}^{n}, x_{3}^{n}\right)-F_{1}\left(x_{1}^{n-1}, x_{2}^{n}, x_{3}^{n}\right)\right\|^{q_{1}}+\left\|A_{1}\left(d_{1}^{n}\right)-A_{1}\left(d_{1}^{n-1}\right)\right\|^{q_{1}} \\
& \quad+q_{1} \rho_{1}^{n} \psi_{1}\left\|F_{1}\left(x_{1}^{n}, x_{2}^{n}, x_{3}^{n}\right)-F_{1}\left(x_{1}^{n-1}, x_{2}^{n}, x_{3}^{n}\right)\right\|^{q_{1}}-\rho_{1}^{n} \kappa_{1}\left\|x_{1}^{n}-x_{1}^{n-1}\right\|^{q_{1}} \\
& \leq\left[c_{q_{1}}\left(\rho^{n}\right)_{1}^{q_{1}} \mu_{11}^{q_{1}}+\gamma_{1}^{q_{1}}\left(1+(n+1)^{-1}\right)^{q_{1}} v_{1}^{q_{1}}+q_{1} \rho_{1}^{n} \psi_{1} \mu_{11}^{q_{1}}-\rho_{1}^{n} \kappa_{1}\right]\left\|x_{1}^{n}-x_{1}^{n-1}\right\|^{q_{1}}, \\
& \quad\left\|F_{1}\left(x_{1}^{n-1}, x_{2}^{n}, x_{3}^{n}\right)-F_{1}\left(x_{1}^{n-1}, x_{2}^{n-1}, x_{3}^{n}\right)\right\| \leq \mu_{12}\left\|x_{2}^{n-1}-x_{2}^{n}\right\|, \\
& \quad\left\|F_{1}\left(x_{1}^{n-1}, x_{2}^{n-1}, x_{3}^{n}\right)-F_{1}\left(x_{1}^{n-1}, x_{2}^{n-1}, x_{3}^{n-1}\right)\right\| \leq \mu_{13}\left\|x_{3}^{n-1}-x_{3}^{n}\right\|, \\
& \left\|G_{1}\left(a_{1}^{n}, a_{2}^{n}, a_{3}^{n}\right)-G_{1}\left(a_{1}^{n-1}, a_{2}^{n-1}, a_{3}^{n-1}\right)\right\| \\
& \leq\left\|G_{1}\left(a_{1}^{n}, a_{2}^{n}, a_{3}^{n}\right)-G_{1}\left(a_{1}^{n-1}, a_{2}^{n}, a_{3}^{n}\right)\right\| \\
& \quad+\left\|G_{1}\left(a_{1}^{n-1}, a_{2}^{n}, a_{3}^{n}\right)-G_{1}\left(a_{1}^{n-1}, a_{2}^{n-1}, a_{3}^{n}\right)\right\| \\
& \quad+\left\|G_{1}\left(a_{1}^{n-1}, a_{2}^{n-1}, a_{3}^{n-1}\right)-G_{1}\left(a_{1}^{n-1}, a_{2}^{n-1}, a_{3}^{n}\right)\right\| \\
& \leq v_{11}\left\|a_{1}^{n-1}-a_{1}^{n}\right\|+v_{12}\left\|a_{2}^{n-1}-a_{2}^{n}\right\|+v_{13}\left\|a_{3}^{n-1}-a_{3}^{n}\right\| .
\end{aligned}
$$

By (3.13), we know that $\left\|x_{1}^{n+1}-x_{1}^{n}\right\|=\alpha_{1}^{n}\left\|y_{1}^{n}-d_{1}^{n}\right\|$. Since $G_{i}: X_{1} \times X_{2} \times X_{3} \rightarrow X_{i}$ is Lipschitz continuous with constants $\left(v_{i 1}, v_{i 2}, v_{i 3}\right)$, and $S_{i}: X_{i} \rightarrow C B\left(X_{i}\right)$ is $D$-Lipschitz continuous with constants $s_{i}$, respectively, combing (4.4)-(4.8) and using Corollary 2.12, we have

$$
\begin{aligned}
& \left(1-\xi_{1}^{n}\right)\left\|x_{1}^{n+1}-x_{1}^{n}\right\| \\
& \leq\left(1-\alpha_{1}^{n}\right)\left\|x_{1}^{n}-x_{1}^{n-1}\right\| \\
& +\alpha_{1}^{n}\left[\left(1+q_{1} \sigma_{1}\left(1+\frac{1}{n+1}\right)^{q_{1}} v_{1}^{q_{1}}-q_{1} \zeta_{1}+c_{q_{1}}\left(1+\frac{1}{n+1}\right)^{q_{1}} v_{1}^{q_{1}}\right)^{1 / q_{1}} \xi_{1}^{n-1} \frac{1}{\alpha_{1}^{n-1}}\right. \\
& \quad+\frac{\tau_{1}^{q_{1}-1}}{r_{1}-m_{1} \rho_{1}^{n}}\left(\left(c_{q_{1}}\left(\rho^{n}\right)_{1}^{q_{1}} \mu_{11}^{q_{1}}+r_{1}^{q_{1}}\left(1+\frac{1}{n+1}\right)^{q_{1}} v_{1}^{q_{1}}+q_{1} \rho_{1}^{n} \psi_{1} \mu_{11}^{q_{1}}-\rho_{1}^{n} \kappa_{1}\right)^{1 / q_{1}}\right. \\
& \left.\left.\quad+\left|\rho_{1}^{n}-\rho_{1}^{n-1}\right|\left(h_{1}+g_{1}+\left\|\varepsilon_{1}\right\|\right)\right)\right]\left\|x_{1}^{n}-x_{1}^{n-1}\right\|
\end{aligned}
$$


Fixed Point Theory and Applications

$$
\begin{array}{r}
+\alpha_{1}^{n} \rho_{1}^{n}\left[\mu_{12}\left\|x_{2}^{n-1}-x_{2}^{n}\right\|+\mu_{13}\left\|x_{3}^{n-1}-x_{3}^{n}\right\|+v_{11}\left(1+\frac{1}{n+1}\right) s_{1}\left\|x_{1}^{n-1}-x_{1}^{n}\right\|\right. \\
\left.+v_{12}\left(1+\frac{1}{n+1}\right) s_{2}\left\|x_{2}^{n-1}-x_{2}^{n}\right\|+v_{13}\left(1+\frac{1}{n+1}\right) s_{3}\left\|x_{3}^{n-1}-x_{3}^{n}\right\|\right],
\end{array}
$$

and so

$$
\begin{aligned}
& \left\|x_{1}^{n+1}-x_{1}^{n}\right\| \\
& \leq \frac{1}{1-\xi_{1}^{n}}\left\{1-\alpha_{1}^{n}\left[1-\left(1+q_{1} \sigma_{1}\left(1+\frac{1}{n+1}\right)^{q_{1}} v_{1}^{q_{1}}-q_{1} \zeta_{1}+c_{q_{1}}\left(1+\frac{1}{n+1}\right)^{q_{1}} v_{1}^{q_{1}}\right)^{1 / q_{1}}-\frac{\xi_{1}^{n-1}}{\alpha_{1}^{n-1}}\right.\right. \\
& -\frac{\tau_{1}^{q_{1}-1}}{r_{1}-m_{1} \rho_{1}^{n}}\left(\left(c_{q_{1}}\left(\rho^{n}\right)_{1}^{q_{1}} \mu_{11}^{q_{1}}+r_{1}^{q_{1}}\left(1+\frac{1}{n+1}\right)^{q_{1}} v_{1}^{q_{1}}+q_{1} \rho_{1}^{n} \psi_{1} \mu_{11}^{q_{1}}-\rho_{1}^{n} \kappa_{1}\right)^{1 / q_{1}}\right. \\
& \left.\left.\left.+\rho_{1}^{n} v_{11}\left(1+\frac{1}{n+1}\right) s_{1}+\left|\rho_{1}^{n}-\rho_{1}^{n-1}\right|\left(h_{1}+g_{1}+\left\|\varepsilon_{1}\right\|\right)\right)\right]\right\} \\
& \times\left\|x_{1}^{n}-x_{1}^{n-1}\right\|+\frac{1}{1-\xi_{1}^{n}} \alpha_{1}^{n} \rho_{1}^{n}\left[\left(\mu_{12}+v_{12}\left(1+\frac{1}{n+1}\right) s_{2}\right)\right]\left\|x_{2}^{n-1}-x_{2}^{n}\right\| \\
& +\frac{1}{1-\xi_{1}^{n}} \alpha_{1}^{n} \rho_{1}^{n}\left[\left(\mu_{13}+v_{13}\left(1+\frac{1}{n+1}\right) s_{3}\right)\left\|x_{3}^{n-1}-x_{3}^{n}\right\|\right] \text {. }
\end{aligned}
$$

For the sequences $\left\{x_{2}^{n}\right\}_{n=0}^{\infty}$, we have

$$
\left\|x_{2}^{n+1}-x_{2}^{n}\right\| \leq\left(1-\alpha_{2}^{n}\right)\left\|x_{2}^{n}-x_{2}^{n-1}\right\|+\alpha_{2}^{n}\left\|x_{2}^{n}-x_{2}^{n-1}-\left(d_{2}^{n}-d_{2}^{n-1}\right)\right\|+\alpha_{2}^{n}\left\|y_{2}^{n}-y_{2}^{n-1}\right\| .
$$

Since $V_{2}: X_{2} \rightarrow C B\left(X_{2}\right)$ is $D$-Lipschitz continuous with constant $v_{2}$ and $\left(\sigma_{2}, \zeta_{2}\right)$-relaxed cocoercive, we have

$$
\begin{aligned}
\| x_{2}^{n} & -x_{2}^{n-1}-\left(d_{2}^{n}-d_{2}^{n-1}\right) \|^{q_{2}} \\
& =\left\|x_{2}^{n}-x_{2}^{n-1}\right\|^{q_{2}}-q_{2}\left\langle x_{2}^{n}-x_{2}^{n-1}, J_{q_{2}}\left(d_{2}^{n}-d_{2}^{n-1}\right)\right\rangle+c_{q_{2}}\left\|d_{2}^{n}-d_{2}^{n-1}\right\|^{q_{2}} \\
& \leq\left(1+q_{2} \sigma_{2}\left(1+\frac{1}{n+1}\right)^{q_{2}} v_{2}^{q_{2}}-q_{2} \zeta_{2}+c_{q_{2}}\left(1+\frac{1}{n+1}\right)^{q_{2}} v_{2}^{q_{2}}\right)\left\|x_{2}^{n}-x_{2}^{n-1}\right\|^{q_{2}} .
\end{aligned}
$$


It follows from (3.15) that

$$
\begin{aligned}
\left\|y_{2}^{n}-y_{2}^{n-1}\right\| \leq & \left\|y_{2}^{n}-R_{\rho_{2}^{n}, M_{2}\left(d_{2},\right)}^{A_{2} 1, \eta_{2}}\left(\Omega_{2}^{n}\right)\right\|+\left\|R_{\rho_{2}^{n}, M_{2}\left(d_{2}, \cdot\right)}^{\left.A_{2,}\right)}\left(\Omega_{2}^{n-1}\right)-y_{2}^{n-1}\right\| \\
& +\left\|R_{\rho_{2}^{n}, M_{2}\left(d_{2},\right)}^{A_{2}, \eta_{2}}\left(\Omega_{2}^{n}\right)-R_{\rho_{2}^{n}, M_{2}\left(d_{2}, \cdot\right)}^{A_{2}, \eta_{2}}\left(\Omega_{2}^{n-1}\right)\right\| \\
\leq & \xi_{2}^{n}\left\|y_{2}^{n}-d_{2}^{n}\right\|+\xi_{2}^{n-1}\left\|y_{2}^{n-1}-d_{2}^{n-1}\right\| \\
& +\left\|R_{\rho_{2}, M_{2}\left(d_{2},\right)}^{A_{2}, \eta_{2}}\left(\Omega_{2}^{n}\right)-R_{\rho_{2}, M_{2}\left(d_{2},\right)}^{A_{2,}, \eta_{2}}\left(\Omega_{2}^{n-1}\right)\right\| .
\end{aligned}
$$

Since $\left\|F_{2}\left(x_{1}, x_{2}, x_{3}\right)\right\| \leq h_{2}$ and $\left\|G_{2}\left(x_{1}, x_{2}, x_{3}\right)\right\| \leq g_{2}$, by using Lemma 2.9, we obtain

$$
\begin{aligned}
\| R_{\rho_{2}^{n}, M_{2}\left(d_{2}, \dot{ }\right.}^{A_{2}, \eta_{2}}\left(\Omega_{2}^{n}\right)- & R_{\rho_{2}^{n}, M_{2}\left(d_{2}, \cdot\right)}^{A_{2}, \eta_{2}}\left(\Omega_{2}^{n-1}\right) \| \\
\leq \frac{\tau_{2}^{q_{2}-1}}{r_{2}-m_{2} \rho_{2}^{n}}\left\|\Omega_{2}^{n}-\Omega_{2}^{n-1}\right\| & \\
\leq \frac{\tau_{2}^{q_{2}-1}}{r_{2}-m_{2} \rho_{2}^{n}}[ & \left\|A_{2}\left(d_{2}^{n}\right)-A_{2}\left(d_{2}^{n-1}\right)-\rho_{2}\left(F_{2}\left(x_{2}^{n}, x_{2}^{n}, x_{2}^{n}\right)-F_{2}\left(x_{2}^{n-1}, x_{2}^{n-1}, x_{2}^{n-1}\right)\right)\right\| \\
& +\rho_{2}^{n}\left\|G_{2}\left(a_{2}^{n}, a_{2}^{n}, a_{2}^{n}\right)-G_{2}\left(a_{2}^{n-1}, a_{2}^{n-1}, a_{2}^{n-1}\right)\right\| \\
& \left.+\left|\rho_{2}^{n}-\rho_{2}^{n-1}\right|\left(h_{2}+g_{2}+\left\|\varepsilon_{2}\right\|\right)\right] \\
\leq \frac{\tau_{2}^{q_{2}-1}}{r_{2}-m_{2} \rho_{2}^{n}}[ & \left\|A_{2}\left(d_{2}^{n}\right)-A_{2}\left(d_{2}^{n-1}\right)-\rho_{2}^{n}\left(F_{2}\left(x_{1}^{n}, x_{2}^{n}, x_{3}^{n}\right)-F_{1}\left(x_{1}^{n}, x_{2}^{n-1}, x_{3}^{n}\right)\right)\right\| \\
& +\rho_{2}^{n}\left\|F_{2}\left(x_{1}^{n}, x_{2}^{n-1}, x_{3}^{n}\right)-F_{2}\left(x_{1}^{n-1}, x_{2}^{n-1}, x_{3}^{n}\right)\right\| \\
& +\rho_{2}^{n}\left\|F_{2}\left(x_{1}^{n-1}, x_{2}^{n-1}, x_{3}^{n}\right)-F_{2}\left(x_{1}^{n-1}, x_{2}^{n-1}, x_{3}^{n-1}\right)\right\| \\
& \left.+\rho_{2}^{2}\left\|G_{2}\left(b_{1}^{n}, b_{2}^{n}, b_{3}^{n}\right)-G_{2}\left(b_{1}^{n-1}, b_{2}^{n-1}, b_{3}^{n-1}\right)\right\|+\left|\rho_{2}^{n}-\rho_{2}^{n-1}\right|\left(h_{2}+g_{2}+\left\|\varepsilon_{2}\right\|\right)\right] .
\end{aligned}
$$

Since $F_{2}: X_{1} \times X_{2} \times X_{3} \rightarrow X_{2}$ is Lipschitz continuous with constants $\mu_{21}, \mu_{22}, \mu_{23}$, and $\left(\psi_{2}, \kappa_{2}\right)$ relaxed cocoercive with respect to $A_{2} S_{2}$ in the first arguments, $G_{i}: X_{1} \times X_{2} \times X_{3} \rightarrow X_{i}$ is 
Lipschitz continuous with constants $\left(v_{i 1}, v_{i 2}, v_{i 3}\right)$, respectively, it follows from Lemma 2.10 that

$$
\begin{aligned}
\left\|A_{2}\left(d_{2}^{n}\right)-A_{2}\left(d_{2}^{n-1}\right)-\rho_{2}\left(F_{2}\left(x_{1}^{n}, x_{2}^{n}, x_{3}^{n}\right)-F_{2}\left(x_{1}^{n}, x_{2}^{n-1}, x_{3}^{n}\right)\right)\right\|^{q_{2}} \\
\leq c_{q_{2}}\left(\rho_{2}^{n}\right)^{q_{2}}\left\|F_{2}\left(x_{1}^{n}, x_{2}^{n}, x_{3}^{n}\right)-F_{2}\left(x_{1}^{n}, x_{2}^{n-1}, x_{3}^{n}\right)\right\|^{q_{2}}+\left\|A_{2}\left(d_{2}^{n}\right)-A_{2}\left(d_{2}^{n-1}\right)\right\|^{q_{2}} \\
\quad-q_{2} \rho_{2}^{n}\left\langle F_{2}\left(x_{1}^{n}, x_{2}^{n}, x_{3}^{n}\right)-F_{2}\left(x_{1}^{n}, x_{2}^{n-1}, x_{3}^{n}\right), J_{q}\left(A_{2}\left(d_{2}^{n}\right)-A_{2}\left(d_{2}^{n-1}\right)\right)\right\rangle \\
\leq c_{q_{2}}\left(\rho_{2}^{n}\right)^{q_{2}}\left\|F_{2}\left(x_{1}^{n}, x_{2}^{n}, x_{3}^{n}\right)-F_{2}\left(x_{1}^{n}, x_{2}^{n-1}, x_{3}^{n}\right)\right\|^{q_{2}}+\left\|A_{2}\left(d_{2}^{n}\right)-A_{2}\left(d_{2}^{n-1}\right)\right\|^{q_{2}} \\
\quad+q_{2} \rho_{2}^{n} \psi_{2}\left\|F_{2}\left(x_{1}^{n}, x_{2}^{n}, x_{3}^{n}\right)-F_{2}\left(x_{1}^{n}, x_{2}^{n-1}, x_{3}^{n}\right)\right\|^{q_{2}}-\rho_{2}^{n} \kappa_{2}\left\|x_{2}^{n}-x_{2}^{n-1}\right\|^{q_{2}} \\
\leq \quad\left[c_{q_{2}}\left(\rho_{2}^{n}\right)^{q_{2}} \mu_{21}^{q_{2}}+r_{2}^{q_{2}}\left(1+\frac{1}{(n+1)}\right)^{q_{2}} v_{2}^{q_{2}}+q_{2} \rho_{2}^{n} \psi_{2} \mu_{21}^{q_{2}}-\rho_{2}^{n} \kappa_{2}\right]\left\|x_{2}^{n}-x_{2}^{n-1}\right\|^{q_{2}}, \\
\left\|F_{2}\left(x_{1}^{n}, x_{2}^{n-1}, x_{3}^{n}\right)-F_{2}\left(x_{1}^{n-1}, x_{2}^{n-1}, x_{3}^{n}\right)\right\| \leq \mu_{21}\left\|x_{1}^{n-1}-x_{1}^{n}\right\|, \\
\left\|G_{2}\left(b_{1}^{n}, b_{2}^{n}, b_{3}^{n}\right)-G_{2}\left(b_{1}^{n-1}, b_{2}^{n-1}, b_{3}^{n-1}\right)\right\| \\
\left.\leq\left\|F_{2}\left(b_{1}^{n}, b_{2}^{n}, b_{3}^{n}\right)-G_{2}\left(b_{1}^{n-1}, b_{2}^{n}, b_{3}^{n}\right)\right\|+\| G_{2}^{n-1}, x_{3}^{n}\right)-F_{2}\left(x_{1}^{n-1}, x_{2}^{n-1}, x_{3}^{n-1}\right)\left\|\leq \mu_{23}^{n}\right\| x_{3}^{n-1}-x_{3}^{n} \|, \\
\quad\left\|G_{2}\left(b_{1}^{n-1}, b_{2}^{n-1}, b_{3}^{n-1}\right)-G_{2}\left(b_{1}^{n-1}, b_{2}^{n-1}, b_{3}^{n}\right)\right\| \\
\left.\leq v_{21}^{n-1}, b_{2}^{n-1}, b_{3}^{n}\right) \|
\end{aligned}
$$

By (3.13), we know that $\left\|x_{2}^{n+1}-x_{2}^{n}\right\|=\alpha_{2}^{n}\left\|y_{2}^{n}-d_{2}^{n}\right\|$. Since $G_{i}: X_{1} \times X_{2} \times X_{3} \rightarrow X_{i}$ is Lipschitz continuous with constants $\left(v_{i 1}, v_{i 2}, v_{i 3}\right)$, and $T_{i}: X_{i} \rightarrow C B\left(X_{i}\right)$ is $D$-Lipschitz continuous with constants $t_{i}$, respectively, combing (4.11)-(4.20) and using Corollary 2.12, we have

$$
\begin{aligned}
& \left(1-\xi_{2}^{n}\right)\left\|x_{2}^{n+1}-x_{2}^{n}\right\| \\
& \leq\left(1-\alpha_{2}^{n}\right)\left\|x_{2}^{n}-x_{2}^{n-1}\right\| \\
& +\alpha_{2}^{n}\left[\left(1+q_{2} \sigma_{2}\left(1+\frac{1}{n+1}\right)^{q_{2}} \mathrm{v}_{1}^{q_{2}}-q_{2} \zeta_{2}+c_{q_{2}}\left(1+\frac{1}{n+1}\right)^{q_{2}} v_{2}^{q_{2}}\right)^{1 / q_{2}} \xi_{2}^{n-1} \frac{1}{\alpha_{2}^{n-1}}\right. \\
& \quad+\frac{\tau_{2}^{q_{2}-1}}{r_{2}-m_{2} \rho_{2}^{n}}\left(\left(c_{q_{2}}\left(\rho_{2}^{n}\right)^{q_{2}} \mu_{22}^{q_{2}}+r_{2}^{q_{2}}\left(1+\frac{1}{n+1}\right)^{q_{2}} v_{2}^{q_{2}}+q_{2} \rho_{2}^{n} \psi_{2} \mu_{22}^{q_{2}}-\rho_{2}^{n} \kappa_{2}\right)^{1 / q_{2}}\right.
\end{aligned}
$$




$$
\begin{gathered}
\left.\left.+\left|\rho_{2}^{n}-\rho_{2}^{n-1}\right|\left(h_{2}+g_{2}+\left\|\varepsilon_{2}\right\|\right)\right)\right]\left\|x_{2}^{n}-x_{2}^{n-1}\right\| \\
+\alpha_{2}^{n} \rho_{2}^{n}\left[\mu_{21}\left\|x_{1}^{n-1}-x_{1}^{n}\right\|+\mu_{23}\left\|x_{3}^{n-1}-x_{3}^{n}\right\|+v_{21}\left(1+\frac{1}{n+1}\right) t_{1}\left\|x_{1}^{n-1}-x_{1}^{n}\right\|\right. \\
\left.+v_{22}\left(1+\frac{1}{n+1}\right) t_{2}\left\|x_{2}^{n-1}-x_{2}^{n}\right\|+v_{23}\left(1+\frac{1}{n+1}\right) t_{3}\left\|x_{3}^{n-1}-x_{3}^{n}\right\|\right],
\end{gathered}
$$

and so

$$
\begin{aligned}
& \left\|x_{2}^{n+1}-x_{2}^{n}\right\| \\
& \begin{aligned}
\leq \frac{1}{1-\xi_{2}^{n}}\left\{1-\alpha_{2}^{n}\left[1-\left(1+q_{2} \sigma_{2}\left(1+\frac{1}{n+1}\right)^{q_{2}} v_{2}^{q_{2}}-q_{2} \zeta_{2}+c_{q_{2}}\left(1+\frac{1}{n+1}\right)^{q_{2}} v_{2}^{q_{2}}\right)^{1 / q_{2}}-\frac{\xi_{2}^{n-1}}{\alpha_{2}^{n-1}}\right.\right. \\
\quad-\frac{\tau_{2}^{q_{2}-1}}{r_{2}-m_{2} \rho_{2}^{n}}\left(\left(c_{q_{2}}\left(\rho_{2}^{n}\right)^{q_{2}} \mu_{22}^{q_{2}}+\gamma_{2}^{q_{2}}\left(1+\frac{1}{n+1}\right)^{q_{2}} v_{2}^{q_{2}}+q_{2} \rho_{2}^{n} \psi_{2} \mu_{22}^{q_{2}}-\rho_{2}^{n} \kappa_{2}\right)^{1 / q_{2}}\right. \\
\left.\left.\left.\quad+\rho_{2}^{n} v_{22}\left(1+\frac{1}{n+1}\right) t_{2}+\left|\rho_{2}^{n}-\rho_{2}^{n-1}\right|\left(h_{2}+g_{2}+\left\|\varepsilon_{2}\right\|\right)\right)\right]\right\} \\
\times\left\|x_{2}^{n}-x_{2}^{n-1}\right\|+\frac{1}{1-\xi_{2}^{n}} \alpha_{2}^{n} \rho_{2}^{n}\left[\left(\mu_{21}+v_{21}\left(1+\frac{1}{n+1}\right) t_{1}\right)\right]\left\|x_{1}^{n-1}-x_{1}^{n}\right\| \\
+\frac{1}{1-\xi_{2}^{n}} \alpha_{2}^{n} \rho_{2}^{n}\left[\left(\mu_{23}+v_{23}\left(1+\frac{1}{n+1}\right) t_{3}\right)\right]\left\|x_{3}^{n-1}-x_{3}^{n}\right\| .
\end{aligned}
\end{aligned}
$$

Using the same as the method, we can obtain

$$
\begin{aligned}
& \left\|x_{3}^{n+1}-x_{3}^{n}\right\| \\
& \leq \frac{1}{1-\xi_{3}^{n}}\left\{1-\alpha_{3}^{n}\left[1-\left(1+q_{3} \sigma_{3}\left(1+\frac{1}{n+1}\right)^{q_{3}} v_{3}^{q_{3}}-q_{3} \zeta_{3}+c_{q_{3}}\left(1+\frac{1}{n+1}\right)^{q_{3}} v_{3}^{q_{3}}\right)^{1 / q_{3}}-\frac{\xi_{3}^{n-1}}{\alpha_{3}^{n-1}}\right.\right. \\
& -\frac{\tau_{3}^{q_{3}-1}}{r_{3}-m_{3} \rho_{3}^{n}}\left(\left(c_{q_{3}}\left(\rho_{3}^{n}\right)^{q_{3}} \mu_{33}^{q_{3}}+r_{3}^{q_{3}}\left(1+\frac{1}{n+1}\right)^{q_{3}} v_{3}^{q_{3}}+q_{3} \rho_{3}^{n} \psi_{3} \mu_{33}^{q_{3}}-\rho_{3}^{n} \kappa_{3}\right)^{1 / q_{3}}\right. \\
& \left.\left.\left.+\rho_{3}^{n} v_{33}\left(1+\frac{1}{n+1}\right) u_{3}+\left|\rho_{3}^{n}-\rho_{3}^{n-1}\right|\left(h_{3}+g_{3}+\left\|\varepsilon_{3}\right\|\right)\right)\right]\right\} \\
& \times\left\|x_{3}^{n}-x_{3}^{n-1}\right\|+\frac{1}{1-\xi_{3}^{n}} \alpha_{3}^{n} \rho_{3}^{n}\left[\left(\mu_{31}+v_{31}\left(1+\frac{1}{n+1}\right) u_{1}\right)\right]\left\|x_{1}^{n-1}-x_{1}^{n}\right\| \\
& +\frac{1}{1-\xi_{3}^{n}} \alpha_{3}^{n} \rho_{3}^{n}\left[\left(\mu_{32}+v_{32}\left(1+\frac{1}{n+1}\right) u_{2}\right)\right]\left\|x_{2}^{n-1}-x_{2}^{n}\right\| \text {. }
\end{aligned}
$$


Fixed Point Theory and Applications

19

Let

$$
\begin{aligned}
& \Gamma_{11}(n)=\frac{1}{1-\xi_{1}^{n}}\left\{1-\alpha_{1}^{n}\left[1-\left(1+q_{1} \sigma_{1}\left(1+\frac{1}{n+1}\right)^{q_{1}} v_{1}^{q_{1}}-q_{1} \zeta_{1}+c_{q_{1}}\left(1+\frac{1}{n+1}\right)^{q_{1}} v_{1}^{q_{1}}\right)^{1 / q_{1}}-\frac{\xi_{1}^{n-1}}{\alpha_{1}^{n-1}}\right.\right. \\
& -\frac{\tau_{1}^{q_{1}-1}}{r_{1}-m_{1} \rho_{1}^{n}}\left(\left(c_{q_{1}}\left(\rho_{1}^{n}\right)^{q_{1}} \mu_{11}^{q_{1}}+r_{1}^{q_{1}}\left(1+\frac{1}{n+1}\right)^{q_{1}} v_{1}^{q_{1}}+q_{1} \rho_{1}^{n} \psi_{1} \mu_{11}^{q_{1}}-\rho_{1} \kappa_{1}\right)^{1 / q_{1}}\right. \\
& \left.\left.\left.+\rho_{1}^{n} v_{11}\left(1+\frac{1}{n+1}\right) s_{1}+()\left|\rho_{1}^{n}-\rho_{1}^{n-1}\right|\left(h_{1}+g_{1}+\left\|\varepsilon_{1}\right\|\right)\right)\right]\right\} \\
& \Gamma_{12}(n)=\frac{1}{1-\xi_{1}^{n}} \alpha_{1}^{n} \rho_{1}^{n}\left[\left(\mu_{12}+v_{12}\left(1+\frac{1}{n+1}\right) s_{2}\right)\right], \\
& \Gamma_{13}(n)=\frac{1}{1-\xi_{1}^{n}} \alpha_{1}^{n} \rho_{1}^{n}\left[\left(\mu_{13}+v_{13}\left(1+\frac{1}{n+1}\right) s_{3}\right)\right] \text {, } \\
& \Gamma_{21}(n)=\frac{1}{1-\xi_{2}^{n}} \alpha_{2}^{n} \rho_{2}^{n}\left[\left(\mu_{21}+v_{21}\left(1+\frac{1}{n+1}\right) t_{1}\right)\right] \text {, } \\
& \Gamma_{22}(n)=\frac{1}{1-\xi_{2}^{n}}\left\{1-\alpha_{2}^{n}\left[1-\left(1+q_{2} \sigma_{2}\left(1+\frac{1}{n+1}\right)^{q_{2}} v_{2}^{q_{2}}-q_{2} \zeta_{2}+c_{q_{2}}\left(1+\frac{1}{n+1}\right)^{q_{2}} v_{2}^{q_{2}}\right)^{1 / q_{2}}-\frac{\xi_{2}^{n-1}}{\alpha_{2}^{n-1}}\right.\right. \\
& -\frac{\tau_{2}^{q_{2}-1}}{r_{2}-m_{2} \rho_{2}^{n}}\left(\left(c_{q_{2}}\left(\rho_{2}^{n}\right)^{q_{2}} \mu_{22}^{q_{2}}+\gamma_{2}^{q_{2}}\left(1+\frac{1}{n+1}\right)^{q_{2}} v_{2}^{q_{2}}+q_{2} \rho_{2}^{n} \psi_{2} \mu_{22}^{q_{2}}-\rho_{2}^{n} \kappa_{2}\right)^{1 / q_{2}}\right. \\
& \left.\left.\left.+\rho_{2}^{n} v_{22}\left(1+\frac{1}{n+1}\right) t_{2}+\left|\rho_{2}^{n}-\rho_{2}^{n-1}\right|\left(h_{2}+g_{2}+\left\|\varepsilon_{2}\right\|\right)\right)\right]\right\}, \\
& \Gamma_{23}(n)=\frac{1}{1-\xi_{2}^{n}} \alpha_{2}^{n} \rho_{2}^{n}\left[\left(\mu_{23}+v_{23}\left(1+\frac{1}{n+1}\right) t_{3}\right)\right], \\
& \Gamma_{31}(n)=\frac{1}{1-\xi_{3}^{n}} \alpha_{3}^{n} \rho_{3}^{n}\left[\left(\mu_{31}+v_{31}\left(1+\frac{1}{n+1}\right) u_{1}\right)\right] \text {, } \\
& \Gamma_{32}(n)=\frac{1}{1-\xi_{3}^{n}} \alpha_{3}^{n} \rho_{3}^{n}\left[\left(\mu_{32}+v_{32}\left(1+\frac{1}{n+1}\right) u_{2}\right)\right] \text {, } \\
& \Gamma_{33}(n)=\frac{1}{1-\xi_{3}^{n}}\left\{1-\alpha_{3}^{n}\left[1-\left(1+q_{3} \sigma_{3}\left(1+\frac{1}{n+1}\right)^{q_{3}} v_{3}^{q_{3}}-q_{3} \zeta_{3}+c_{q_{3}}\left(1+\frac{1}{n+1}\right)^{q_{3}} v_{3}^{q_{3}}\right)^{1 / q_{3}}-\frac{\xi_{3}^{n-1}}{\alpha_{3}^{n-1}}\right.\right. \\
& -\frac{\tau_{3}^{q_{3}-1}}{r_{3}-m_{3} \rho_{3}^{n}}\left(\left(c_{q_{3}}\left(\rho_{3}^{n}\right)^{q_{3}} \mu_{33}^{q_{3}}+\gamma_{3}^{q_{3}}\left(1+\frac{1}{n+1}\right)^{q_{3}} v_{3}^{q_{3}}+q_{3} \rho_{3}^{n} \psi_{3} \mu_{33}^{q_{3}}-\rho_{3}^{n} \kappa_{3}\right)^{1 / q_{3}}\right. \\
& \left.\left.\left.+\rho_{3}^{n} v_{33}\left(1+\frac{1}{n+1}\right) u_{3}+\left|\rho_{3}^{n}-\rho_{3}^{n-1}\right|\left(h_{3}+g_{3}+\left\|\varepsilon_{3}\right\|\right)\right)\right]\right\} .
\end{aligned}
$$


Letting $\vec{a}(n+1)=\left(\left\|x_{1}^{n+1}-x_{1}^{n}\right\|,\left\|x_{2}^{n+1}-x_{2}^{n}\right\|,\left\|x_{3}^{n+1}-x_{3}^{n}\right\|\right)^{T}(n=0,1,2, \ldots)$, then combining (4.10),(4.17)-(4.19), we have $\vec{a}(n+1) \leq \Psi(\omega, n) \vec{a}(n)$, where

$$
\Psi(\omega, n)=\left(\begin{array}{lll}
\Gamma_{11}(n) & \Gamma_{12}(n) & \Gamma_{13}(n) \\
\Gamma_{21}(n) & \Gamma_{22}(n) & \Gamma_{23}(n) \\
\Gamma_{31}(n) & \Gamma_{32}(n) & \Gamma_{33}(n)
\end{array}\right)
$$

which is called the iterative matrix for Hybrid proximal point three-step algorithm of nonlinear set-valued quasi-variational inclusions system involving $(A, \eta)$-Accretive mappings. Using (4.20), $\lim _{n \rightarrow \infty} \xi_{i}^{n}=0, \alpha=\limsup _{n \rightarrow \infty} \alpha_{i}^{n}<1, \rho_{i}=\lim _{n \rightarrow \infty} \rho_{i}^{n} \leq \infty$, we have

$$
\Psi(\omega)=\limsup _{n \rightarrow \infty}\left(\begin{array}{lll}
\Gamma_{11}(n) & \Gamma_{12}(n) & \Gamma_{13}(n) \\
\Gamma_{21}(n) & \Gamma_{22}(n) & \Gamma_{23}(n) \\
\Gamma_{31}(n) & \Gamma_{32}(n) & \Gamma_{33}(n)
\end{array}\right)=\left(\begin{array}{lll}
\Gamma_{11} & \Gamma_{12} & \Gamma_{13} \\
\Gamma_{21} & \Gamma_{22} & \Gamma_{23} \\
\Gamma_{31} & \Gamma_{32} & \Gamma_{33}
\end{array}\right),
$$

where $\lim \sup _{n \rightarrow \infty} \Gamma_{i j}(n)=\Gamma_{i j}(i, j=1,2,3)$, and

$$
\begin{aligned}
& \Gamma_{11}=1-\alpha_{1}\left[1-\left(1+q_{1} \sigma_{1} v_{1}^{q_{1}}-q_{1} \zeta_{1}+c_{q_{1}} v_{1}^{q_{1}}\right)^{1 / q_{1}}-\frac{\tau_{1}^{q_{1}-1}}{r_{1}-m_{1} \rho_{1}}\right. \\
& \left.\times\left(c_{q_{1}} \rho_{1}^{q_{1}} \mu_{11}^{q_{1}}+\gamma_{1}^{q_{1}} v_{1}^{q_{1}}+q_{1} \rho_{1} \psi_{1} \mu_{11}^{q_{1}}-\rho_{1} \kappa_{1}\right)^{1 / q_{1}}+\rho_{1} v_{11} s_{1}\right], \\
& \Gamma_{12}=\alpha_{1} \rho_{1}\left(\mu_{12}+\nu_{12} s_{2}\right), \\
& \Gamma_{13}=\alpha_{1} \rho_{1}\left(\mu_{13}+v_{13} s_{3}\right), \\
& \Gamma_{21}=\alpha_{2} \rho_{2}\left(\mu_{21}+\nu_{21} t_{1}\right) \text {, } \\
& \Gamma_{22}=1-\alpha_{2}\left[1-\left(1+q_{2} \sigma_{2} v_{2}^{q_{2}}-q_{2} \zeta_{2}+c_{q_{2}} v_{2}^{q_{2}}\right)^{1 / q_{2}}-\frac{\tau_{2}^{q_{2}-1}}{r_{2}-m_{2} \rho_{2}}\right. \\
& \left.\times\left(c_{q_{2}} \rho_{2}^{q_{2}} \mu_{22}^{q_{2}}+\gamma_{2}^{q_{2}} v_{2}^{q_{2}}+q_{2} \rho_{2} \psi_{2} \mu_{22}^{q_{2}}-\rho_{2} \kappa_{2}\right)^{1 / q_{2}}+\rho_{2} \nu_{22} t_{2}\right], \\
& \Gamma_{23}=\alpha_{2} \rho_{2}\left[\left(\mu_{23}+v_{23} t_{3}\right)\right], \\
& \Gamma_{31}=\alpha_{3} \rho_{3}\left[\left(\mu_{31}+v_{31} u_{1}\right)\right] \text {, } \\
& \Gamma_{32}=\alpha_{3}^{n} \rho_{3}\left[\left(\mu_{32}+v_{32} u_{2}\right)\right] \text {, } \\
& \Gamma_{33}=1-\alpha_{3}\left[1-\left(1+q_{3} \sigma_{3} v_{3}^{q_{3}}-q_{3} \zeta_{3}+c_{q_{3}} v_{3}^{q_{3}}\right)^{1 / q_{3}}-\frac{\tau_{3}^{q_{3}-1}}{r_{3}-m_{3} \rho_{3}}\right. \\
& \left.\times\left(c_{q_{3}} \rho_{3}^{q_{3}} \mu_{33}^{q_{3}}+r_{3}^{q_{3}} v_{3}^{q_{3}}+q_{3} \rho_{3} \psi_{3} \mu_{33}^{q_{3}}-\rho_{3} \kappa_{3}\right)^{1 / q_{3}}+\rho_{3} v_{33} u_{3}\right] .
\end{aligned}
$$


By using [38], we have

$$
\|\vec{a}(n+1)\| \leq\|\Psi(\omega, n)\|\|\vec{a}(n)\|
$$

Letting

$$
\|\Psi(\omega)\|=\max \left\{\Gamma_{11}, \Gamma_{12}, \Gamma_{13}, \Gamma_{21}, \Gamma_{22}, \Gamma_{23}, \Gamma_{31}, \Gamma_{32}, \Gamma_{33}\right\}
$$

It follows from (4.22) and assumption condition (4.2) that $0<\|\Psi(\omega)\|<1$ and hence there exists $N_{0}>0$ and $\|\Psi(\omega)\|_{*} \in(\|\Psi(\omega)\|, 1)$ such that $\Psi(\omega, n)<\|\Psi(\omega)\|_{*}$ for all $n \geq N_{0}$. Therefore, by (4.23), we have

$$
\|\vec{a}(n+1)\| \leq\|\Psi(\omega)\|_{*}^{n}\|\vec{a}(1)\|, \quad \forall n \geq N_{0}
$$

Without loss of generality we assume

$$
\|\vec{a}(n+1)\| \leq\|\Psi(\omega)\|_{*}^{n}\|\vec{a}(1)\|, \quad \forall n \geq 1
$$

By the property of the matrix norm [38], for $n \geq 1$, we have

$$
\left\|x_{i}^{n+1}-x_{i}^{n}\right\| \leq\|\vec{a}(n+1)\| \leq\|\Psi(\omega)\|_{*}^{n}\|\vec{a}(1)\|
$$

Hence, for any $m>n>0$ and $i=1,2,3$, we have

$$
\left\|x_{i}^{m}-x_{i}^{n}\right\| \leq \sum_{k=n}^{m-1}\left\|x_{i}^{k+1}-x_{i}^{k}\right\| \leq \sum_{k=n}^{m-1}\|\Psi(\omega)\|_{*}^{n}\|\vec{a}(1)\| .
$$

It follows that $\left\|x_{i}^{m}-x_{i}^{n}\right\| \rightarrow 0$, as $n \rightarrow \infty$, and so that the $\left\{x_{i}^{n}\right\}$ is a Cauchy sequence in $\mathbf{X}$. Let $x_{i}^{n} \rightarrow x_{i}^{*}$ as $n \rightarrow \infty$. By the Lipschitz continuity of $S_{i}(\cdot), T_{i}(\cdot), U_{i}(\cdot), V_{i}(\cdot)$, we can obtain

$$
\begin{gathered}
\left\|a_{i}^{n+1}-a_{i}^{n}\right\| \leq\left(1+n^{-1}\right) D\left(S_{i}\left(x_{i}^{n+1}\right), S_{i}\left(x_{i}^{n}\right)\right) \leq\left(1+n^{-1}\right) s_{i}\left\|x_{i}^{n+1}-x_{i}^{n}\right\|, \\
\left\|b_{i}^{n+1}-b_{i}^{n}\right\| \leq\left(1+n^{-1}\right) D\left(T_{i}\left(x_{i}^{n+1}\right), T_{i}\left(x_{i}^{n}\right)\right) \leq\left(1+n^{-1}\right) t_{i}\left\|x_{i}^{n+1}-x_{i}^{n}\right\|, \\
\left\|c_{i}^{n+1}-c_{i}^{n}\right\| \leq\left(1+n^{-1}\right) D\left(U_{i}\left(x_{i}^{n+1}\right), U_{i}\left(x_{i}^{n}\right)\right) \leq\left(1+n^{-1}\right) u_{i}\left\|x_{i}^{n+1}-x_{i}^{n}\right\|, \\
\left\|d_{i}^{n+1}-d_{i}^{n}\right\| \leq\left(1+n^{-1}\right) D\left(V_{i}\left(x_{i}^{n+1}\right), V_{i}\left(x_{i}^{n}\right)\right) \leq\left(1+n^{-1}\right) v_{i}\left\|x_{i}^{n+1}-x_{i}^{n}\right\| .
\end{gathered}
$$


It follows that $\left\{a_{i}^{n}\right\},\left\{b_{i}^{n}\right\},\left\{c_{i}^{n}\right\}$, and $\left\{d_{i}^{n}\right\}$ are also Cauchy sequences in $X_{i}$. We can assume that $a_{i}^{n} \rightarrow a_{i}^{*}, b_{i}^{n} \rightarrow b_{i}^{*}, c_{i}^{n} \rightarrow c_{i}^{*}$, and $d_{n} \rightarrow d_{i}^{*}$, respectively. Noting that $a_{i}^{n} \in S_{i}\left(x_{i}^{n}\right)$, we have

$$
\begin{aligned}
d\left(a_{i}^{*}, S_{i}\left(x_{i}^{*}\right)\right) & \leq\left\|a_{i}^{*}-a_{i}^{n}\right\|+d\left(a_{i}^{n}, S_{i}\left(x_{i}^{*}\right)\right) \\
& \leq\left\|a_{i}^{*}-a_{i}^{n}\right\|+D\left(S_{i}\left(x_{i}^{n}\right), S_{i}\left(x_{i}^{*}\right)\right) \\
& \leq\left\|a_{i}^{*}-a_{i}^{n}\right\|+s_{i}\left\|x_{i}^{n}-x_{i}^{*}\right\| \longrightarrow 0 \quad(n \longrightarrow \infty) .
\end{aligned}
$$

Hence $d\left(a_{i}^{*}, S_{i}\left(x_{i}^{*}\right)\right)=0$ and therefore $a_{i}^{*} \in S_{i}\left(x_{i}^{*}\right)$. Similarly, we can prove that $b_{i}^{*} \in T_{i}\left(x_{i}^{*}\right)$, $c_{i}^{*} \in U_{i}\left(x_{i}^{*}\right)$, and $d_{i}^{*} \in V_{i}\left(x_{i}^{*}\right)$. By the Lipschitz continuity of $S_{i}\left(x_{i}^{*}\right), T_{i}\left(x_{i}^{*}\right), U_{i}\left(x_{i}^{*}\right)$, and $V_{i}\left(x_{i}^{*}\right)$, we have

$$
\begin{aligned}
& d_{1}^{*}=R_{\rho_{1}, M_{1}\left(d_{1}^{*},\right)}^{A_{1}, \eta_{1}}\left(A_{1}\left(d_{1}^{*}\right)+\rho_{1} \varepsilon_{1}+\rho_{1} G_{1}\left(a_{1}^{*}, a_{2}^{*}, a_{3}^{*}\right)-\rho_{1} F_{1}\left(x_{1}^{*}, x_{2}^{*}, x_{3}^{*}\right)\right), \\
& d_{2}^{*}=R_{\rho_{2}, M_{1}\left(d_{2}^{*},\right)}^{A_{2}, \eta_{2}}\left(A_{1}\left(d_{2}^{*}\right)+\rho_{2} \varepsilon_{2}+\rho_{2} G_{2}\left(b_{1}^{*}, b_{2}^{*}, b_{3}^{*}\right)-\rho_{2} F_{2}\left(x_{1}^{*}, x_{2}^{*}, x_{3}^{*}\right)\right), \\
& d_{3}^{*}=R_{\rho_{3}, M_{3}\left(d_{3}^{*},\right)}^{A_{3}, \eta_{3}}\left(A_{3}\left(d_{3}^{*}\right)+\rho_{3} \varepsilon_{3}+\rho_{3} G_{3}\left(c_{1}^{*}, c_{2}^{*}, c_{3}^{*}\right)-\rho_{3} F_{3}\left(x_{1}^{*}, x_{2}^{*}, x_{3}^{*}\right)\right)
\end{aligned}
$$

for $i=1,2,3$, where $\rho_{i}>0$ is a constant. Thus, by Theorem (3.3), we know that $\left(x_{i}^{*}, a_{i}^{*}, b_{i}^{*}, c_{i}^{*}, d_{i}^{*}\right)_{i=1}^{3}$ is solution of problem (3.2). This completes the proof.

Corollary 4.2. Let $X_{i}$ be a $q_{i}$-uniformly smooth Banach space, $\eta_{i}: X_{i} \times X_{i} \rightarrow X_{i}$ be a $\tau_{i}$-Lipschtiz continuous mapping, and $A_{i}: X_{i} \rightarrow X_{i}$ be an $r_{i}$-strongly $\eta_{i}$-accretive mapping and $\gamma_{i}$-Lipschitz continuous. Let $S_{i}, T_{i}, U_{i}, V_{i}, F_{i}, G_{i}, M_{1}, M_{2}, M_{3}$ be the same as in Theorem 4.1. If

$$
\begin{aligned}
\sum_{i=1}^{3}( & \left.+q_{i} \sigma_{i} v_{i}^{q_{i}}-q_{i} \zeta_{i}+c_{q_{i}} v_{i}^{q_{i}}\right)^{1 / q_{i}}-\sum_{i=1}^{3} \frac{\tau_{i}^{q_{i}-1}}{r_{i}-m_{i} \rho_{i}}\left(c_{q_{i}} \rho_{i}^{q_{i}} \mu_{i i}^{q_{i}}+\gamma_{i}^{q_{i}} v_{i}^{q_{i}}+q_{i} \rho_{i} \psi_{i} \mu_{11}^{q_{i}}-\rho_{1} \kappa_{1}\right)^{1 / q_{i}} \\
& +\alpha_{1} \rho_{1}\left(\mu_{12}+v_{12} s_{2}+\mu_{13}+v_{13} s_{3}\right)+\left(\rho_{3} v_{33} u_{3}+\rho_{1} v_{11} s_{1}+\rho_{2} v_{22} t_{2}\right) \\
& +\alpha_{2} \rho_{2}\left(\mu_{21}+v_{21} t_{1}+\mu_{23}+v_{23} t_{3}\right)+\alpha_{3} \rho_{3}\left(\mu_{31}+v_{31} u_{1}+\mu_{32}+v_{32} u_{2}\right)<1
\end{aligned}
$$

where $c_{q_{i}}>0$ is the same as in Lemma 2.10, $\rho_{i} \in\left(0, r_{i} / m_{i}\right)$, and $i=1,2,3$. Then problem (3.2) has a solution $\left(x_{i}^{*}, a_{i}^{*}, b_{i}^{*}, c_{i}^{*}, d_{i}^{*}\right)(i=1,2,3)$.

Remark 4.3. For a suitable choice of the mappings $A_{i}, \eta_{i}, F_{i}, M_{i}, G_{i}, \varepsilon_{i}, S_{i}, T_{i}, U_{i}, V_{i}(i=1,2,3)$, we can obtain several known results in $[2-5,9,11-27,29,32-37]$ as special cases of Theorem 4.1 and Corollary 4.2 .

\section{Acknowledgment}

The authors acknowledge the support of the Educational Science Foundation of Chongqing, Chongqing (KJ091315). 


\section{References}

[1] A. Hassouni and A. Moudafi, "A perturbed algorithm for variational inclusions," Journal of Mathematical Analysis and Applications, vol. 185, no. 3, pp. 706-712, 1994.

[2] X. P. Ding and C. L. Luo, "Perturbed proximal point algorithms for general quasi-variational-like inclusions," Journal of Computational and Applied Mathematics, vol. 113, no. 1-2, pp. 153-165, 2000.

[3] R. U. Verma, "A-monotonicity and applications to nonlinear variational inclusion problems," Journal of Applied Mathematics and Stochastic Analysis, no. 2, pp. 193-195, 2004.

[4] R. U. Verma, "Projection methods, algorithms, and a new system of nonlinear variational inequalities," Computers \& Mathematics with Applications, vol. 41, no. 7-8, pp. 1025-1031, 2001.

[5] N.-J. Huang, "Nonlinear implicit quasi-variational inclusions involving generalized $m$-accretive mappings," Archives of Inequalities and Applications, vol. 2, no. 4, pp. 413-425, 2004.

[6] Y. P. Fang, Y. J. Cho, and J. K. Kin, " $(H, \eta)$-accretive operators and approximating solutions for systems of variational inclusions in Banach spaces," to appear in Applied Mathematics Letters.

[7] Y.-P. Fang and N.-J. Huang, "H-accretive operators and resolvent operator technique for solving variational inclusions in Banach spaces," Applied Mathematics Letters, vol. 17, no. 6, pp. 647-653, 2004.

[8] Y.-P. Fang, N.-J. Huang, and H. B. Thompson, "A new system of variational inclusions with $(H, \eta)$ monotone operators in Hilbert spaces," Computers \& Mathematics with Applications, vol. 49, no. 2-3, pp. 365-374, 2005.

[9] H.-Y. Lan, Y. J. Cho, and R. U. Verma, “Nonlinear relaxed cocoercive variational inclusions involving $(A, \eta)$-accretive mappings in Banach spaces," Computers $\mathcal{E}$ Mathematics with Applications, vol. 51, no. 9-10, pp. 1529-1538, 2006.

[10] Q.-B. Zhang, X.-P. Ding, and C.-Z. Cheng, "Resolvent operator technique for generalized implicit variational-like inclusion in Banach space," Journal of Mathematical Analysis and Applications, vol. 361, no. 2, pp. 283-292, 2010.

[11] J. Eckstein and D. P. Bertsekas, "On the Douglas-Rachford splitting method and the proximal point algorithm for maximal monotone operators," Mathematical Programming, vol. 55, no. 1-3, pp. 293-318, 1992.

[12] R. U. Verma, "A hybrid proximal point algorithm based on the $(A, \eta)$-maximal monotonicity framework," Applied Mathematics Letters, vol. 21, no. 2, pp. 142-147, 2008.

[13] S. H. Shim, S. M. Kang, N. J. Huang, and Y. J. Cho, "Perturbed iterative algorithms with errors for completely generalized strongly nonlinear implicit quasivariational inclusions," Journal of Inequalities and Applications, vol. 5, no. 4, pp. 381-395, 2000.

[14] J.-W. Peng and D.-L. Zhu, "Three-step iterative algorithm for a system of set-valued variational inclusions with $(H, \eta)$-monotone operators," Nonlinear Analysis: Theory, Methods \& Applications, vol. 68, no. 1, pp. 139-153, 2008.

[15] G. Cohen and F. Chaplais, "Nested monotony for variational inequalities over product of spaces and convergence of iterative algorithms," Journal of Optimization Theory and Applications, vol. 59, no. 3, pp. 369-390, 1988.

[16] M. Bianchi, "Pseudo P-monotone operators and variational inequalities," Tech. Rep. 6, Istituto di Econometria e Matematica per le Decisioni Economiche, Universita Cattolica del Sacro Cuore, Milan, Italy, 1993.

[17] Q. H. Ansari and J.-C. Yao, "A fixed point theorem and its applications to a system of variational inequalities," Bulletin of the Australian Mathematical Society, vol. 59, no. 3, pp. 433-442, 1999.

[18] Q. H. Ansari, S. Schaible, and J. C. Yao, "System of vector equilibrium problems and its applications," Journal of Optimization Theory and Applications, vol. 107, no. 3, pp. 547-557, 2000.

[19] E. Allevi, A. Gnudi, and I. V. Konnov, "Generalized vector variational inequalities over product sets," Nonlinear Analysis: Theory, Methods E Applications, vol. 47, no. 1, pp. 573-582, 2001.

[20] G. Kassay and J. Kolumbán, "System of multi-valued variational inequalities," Publicationes Mathematicae Debrecen, vol. 56, no. 1-2, pp. 185-195, 2000.

[21] G. Kassay, J. Kolumbán, and Z. Páles, "Factorization of Minty and Stampacchia variational inequality systems," European Journal of Operational Research, vol. 143, no. 2, pp. 377-389, 2002.

[22] J. K. Kim and D. S. Kim, "A new system of generalized nonlinear mixed variational inequalities in Hilbert spaces," Journal of Convex Analysis, vol. 11, no. 1, pp. 235-243, 2004.

[23] Y. J. Cho, Y. P. Fang, N. J. Huang, and H. J. Hwang, "Algorithms for systems of nonlinear variational inequalities," Journal of the Korean Mathematical Society, vol. 41, no. 3, pp. 489-499, 2004.

[24] R. P. Agarwal, Y. J. Cho, and N. J. Huang, "Sensitivity analysis for strongly nonlinear quasi-variational inclusions," Applied Mathematics Letters, vol. 13, no. 6, pp. 19-24, 2000. 
[25] K. R. Kazmi and M. I. Bhat, "Iterative algorithm for a system of nonlinear variational-like inclusions," Computers $\mathcal{E}$ Mathematics with Applications, vol. 48, no. 12, pp. 1929-1935, 2004.

[26] Y. P. Fang and N. J. Huang, "H-monotone operators and system of variational inclusions," Communications on Applied Nonlinear Analysis, vol. 11, no. 1, pp. 93-101, 2004.

[27] W.-Y. Yan, Y.-P. Fang, and N.-J. Huang, "A new system of set-valued variational inclusions with $H$ monotone operators," Mathematical Inequalities \& Applications, vol. 8, no. 3, pp. 537-546, 2005.

[28] Y.-Z. Zou and N.-J. Huang, "H(·, )-accretive operator with an application for solving variational inclusions in Banach spaces," Applied Mathematics and Computation, vol. 204, no. 2, pp. 809-816, 2008.

[29] H. K. Xu, "Inequalities in Banach spaces with applications," Nonlinear Analysis: Theory, Methods $\mathcal{E}$ Applications, vol. 16, no. 12, pp. 1127-1138, 1991.

[30] Y.-Z. Zou and N.-J. Huang, "A new system of variational inclusions involving $H(\cdot, \cdot)$-accretive operator in Banach spaces," Applied Mathematics and Computation, vol. 212, no. 1, pp. 135-144, 2009.

[31] R. U. Verma, "Generalized system for relaxed cocoercive variational inequalities and projection methods," Journal of Optimization Theory and Applications, vol. 121, no. 1, pp. 203-210, 2004.

[32] S.-S. Chang, Y. J. Cho, and H. Zhou, Iterative Methods for Nonlinear Operator Equations in Banach Spaces, Nova Science, Huntington, NY, USA, 2002.

[33] X. Weng, "Fixed point iteration for local strictly pseudo-contractive mapping," Proceedings of the American Mathematical Society, vol. 113, no. 3, pp. 727-731, 1991.

[34] R. P. Agarwal, N.-J. Huang, and M.-Y. Tan, "Sensitivity analysis for a new system of generalized nonlinear mixed quasi-variational inclusions," Applied Mathematics Letters, vol. 17, no. 3, pp. 345-352, 2004.

[35] N.-J. Huang and Y.-P. Fang, "A new class of general variational inclusions involving maximal $\eta$ monotone mappings," Publicationes Mathematicae Debrecen, vol. 62, no. 1-2, pp. 83-98, 2003.

[36] M.-M. Jin, "Perturbed algorithm and stability for strongly nonlinear quasi-variational inclusion involving $H$-accretive operators," Mathematical Inequalities $\mathcal{E}$ Applications, vol. 9, no. 4, pp. 771-779, 2006.

[37] J. Peng and X. Yang, "On existence of a solution for the system of generalized vector quasi-equilibrium problems with upper semicontinuous set-valued maps," International Journal of Mathematics and Mathematical Sciences, no. 15, pp. 2409-2420, 2005.

[38] R. A. Horn and C. R. Johnson, Matrix Analysis, Cambridge University Press, Cambridge, UK, 1985.

[39] S. B. Nadler Jr., "Multi-valued contraction mappings," Pacific Journal of Mathematics, vol. 30, pp. 475$488,1969$. 